\title{
Dynamics of the circulation in the Sea of Marmara: numerical modeling experiments and observations from the Turkish straits system experiment
}

\author{
Jacopo Chiggiato • Ewa Jarosz • Jeffrey W. Book • \\ James Dykes • Lucio Torrisi • Pierre-Marie Poulain • \\ Riccardo Gerin • Jochen Horstmann • Şükrü Beșiktepe
}

Received: 17 January 2011 /Accepted: 1 August 2011 / Published online: 17 August 2011

(C) The Author(s) 2011. This article is published with open access at Springerlink.com

\begin{abstract}
During September 2008 and February 2009, the NR/V Alliance extensively sampled the waters of the Sea of Marmara within the framework of the Turkish Straits System (TSS) experiment coordinated by the NATO Undersea Research Centre. The observational effort provided an opportunity to set up realistic numerical experiments for modeling the observed variability of the Marmara Sea upper layer circulation at mesoscale resolution over the entire basin during the trial period, complementing relevant features and forcing factors revealed by numerical model results with information acquired from in situ and remote sensing datasets. Numerical model solutions from realistic
\end{abstract}

Responsible Editor: Pierre Lermusiaux

This article is part of the Topical Collection on Maritime Rapid Environmental Assessment

J. Chiggiato $(\bowtie) \cdot J$. Horstmann $\cdot$ Ș. Beșiktepe

NATO Undersea Research Centre,

La Spezia, Italy

e-mail: chiggiato@nurc.nato.int

E. Jarosz $\cdot$ J. W. Book $\cdot$ J. Dykes

Naval Research Laboratory,

Stennis Space Center, MS, USA

L. Torrisi

CNMCA, Italian National Meteorological Service,

Rome, Italy

P.-M. Poulain • R. Gerin

Istituto Nazionale di Oceanografia e Geofisica Sperimentale,

Trieste, Italy

Ş. Beşiktepe

Institute of Marine Sciences and Technology, Dokuz Eylül

University,

Izmir, Turkey runs using the Regional Ocean Modeling System (ROMS) produce a general circulation in the Sea of Marmara that is consistent with previous knowledge of the circulation drawn from past hydrographic measurements, with a westward meandering current associated with a recurrent large anticyclone. Additional idealized numerical experiments illuminate the role various dynamics play in determining the Sea of Marmara circulation and pycnocline structure. Both the wind curl and the strait flows are found to strongly influence the strength and location of the main mesoscale features. Large displacements of the pycnocline depth were observed during the sea trials. These displacements can be interpreted as storm-driven upwelling/ downwelling dynamics associated with northeasterly winds; however, lateral advection associated with flow from the Straits also played a role in some displacements.

Keywords Sea of Marmara - Strait of Istanbul - Bosphorus · Numerical ocean modeling - Coastal ocean circulation . Upwelling dynamics $\cdot$ ROMS ocean model

\section{Introduction}

The Sea of Marmara is a semi-enclosed basin with limited size (roughly $250 \times 70 \mathrm{~km}$ ) connected through the Strait of Istanbul (SOI, also known as Bosphorus Strait) to the Black Sea and through the Strait of Çanakkale (SOC, also known as Dardanelles Strait) to the Aegean Sea (Mediterranean Sea). Its depth varies from a shallow, gently sloping shelf along its southern boundary to steep bathymetry near its northern edge, with three deep depressions in the interior (Fig. 1). The Sea of Marmara and the two straits form the Turkish Straits System. The hydrography of the Sea of 


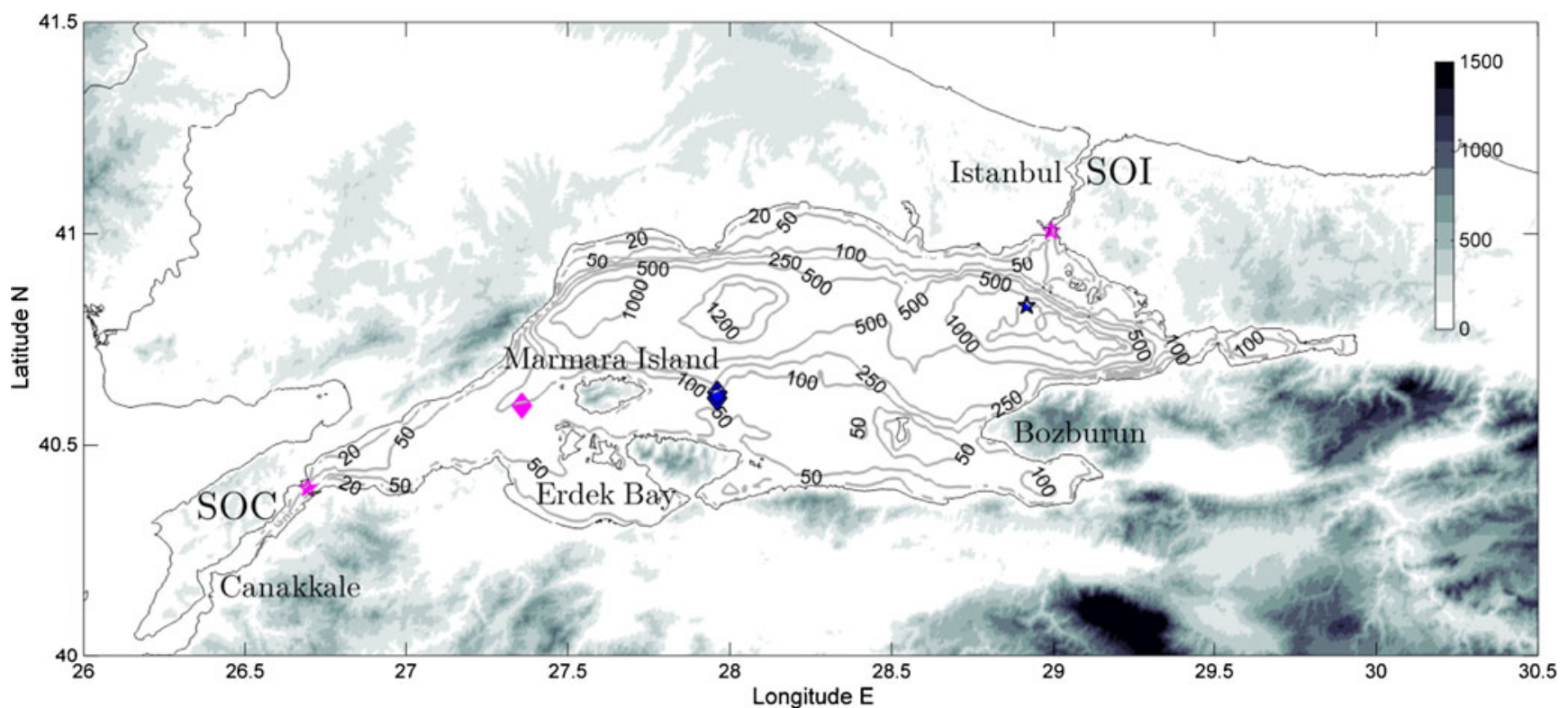

Fig. 1 Geographical map of the Sea of Marmara along with the surrounding orography (color scale, in meters). Contour lines are isobaths. The blue diamonds represent the location of the meteorological buoy (during September 2008 and February 2009), the

Marmara has been the subject of several research initiatives, particularly in the last two decades of the twentieth century, and a thorough review of these is provided by Beşiktepe et al. (1994). The two-layer stratification and two-layer current systems in the straits and in the Sea of Marmara are driven by the density and sea-level differences between the adjoining seas. The persistence of these two layer structures are due to salinity differences. Low salinity Black Sea waters ( 18 PSU) flows into the Marmara Sea through the SOI and denser, salty Aegean waters ( 38.5 PSU) water flows into the Sea of Marmara through the SOC. The two different water masses are separated by a sharp pycnocline at a depth of roughly 25 m (Beşiktepe et al. 1994).

While the dynamics of the Straits of Istanbul and Çanakkale attracted considerable attention, literature on the numerical modeling of the general circulation of the Sea of Marmara is nearly absent and significantly idealized (e.g., Demyshev and Dovgaya 2007). It is important to develop numerical modeling studies in the region for numerous reasons, such as to support risk mitigation for the pollution associated with the presence of the metropolitan area of Istanbul (Burak 2008), and the pollution associated with the heavy ship traffic and accidental oil spillage through the Turkish Straits System (Dogan and Burak 2007; Alpar and Ünlü 2007). Knowledge of the physical background is also important to understand the marine ecology of the region since the Sea of Marmara can be considered a buffer zone between two different ecosystems (Black Sea and the Mediterranean Sea). magenta diamond is the location of the SEPTR, the blue star is the location of the mooring NURC-M4, and the magenta stars represent the location of the NRL moorings and bottom-mounted ADCPs

Between August 2008 and March 2009, international scientific programs "Turkish Straits System (TSS) 2008" and "TSS 2009" were carried out under the coordination of the NATO Undersea Research Centre (NURC) in collaboration with the Naval Research Laboratory (NRL) project "Exchange Processes in Ocean Straits". During September 2008 and February 2009, the NR/V Alliance extensively sampled the waters of the Sea of Marmara with deployments of several instruments [e.g., Conductivity/Temperature/Depth (CTD) rosette, current meter moorings, bottommounted Acoustic Doppler Current Profilers (ADCPs), surface Lagrangian drifters, wave riders, and meteorological buoys] providing time series of current, hydrographic, and meteorological observations. The observational effort provided an opportunity to set up realistic numerical experiments for modeling the circulation in the Sea of Marmara. The objective of this work is to simulate the observed variability of the Marmara Sea upper layer circulation at mesoscale resolution over the entire basin during the trial period. The effort will be the first attempt for realistic simulation of the Sea of Marmara circulation using data from both straits and the basin.

This paper describes relevant mesoscale features and forcing factors revealed by numerical model results. It also assesses model performance, identifies critical issues, and complements information acquired from in situ and remote sensing datasets. The modeling system is described in Section 2. Section 3 discusses the meteorological setting during the experiment. Model results, the general circulation, and a response of the basin to a severe disturbance are 
described in Section 4. Discussion and conclusions are given in Sections 5 and 6.

\section{Modeling system}

The ocean model employed in this application is the Regional Ocean Modeling System (ROMS, Haidvogel et al. 2008). ROMS is a primitive equation, finite difference, hydrostatic, free surface model. It uses generalized terrain following s-coordinates, a staggered Arakawa $\mathrm{C}$ grid in the horizontal, and a split-explicit, non-homogeneous predictor/ corrector time stepping. The ROMS kernel is described in detail by Shchepetkin and McWilliams (2005).

The Sea of Marmara application has been configured on an orthogonal curvilinear grid with a variable horizontal resolution: an average of $1 \mathrm{~km}$ horizontal resolution in the domain with higher resolution $(\sim 500 \mathrm{~m})$ near the SOI and $\sim 1.5 \mathrm{~km}$ in the central part of the basin. The inner part of both straits included in the grid has been linearized for numerical reasons, with rectification of the direction and a flat constant depth $(50 \mathrm{~m}$ in the SOI, $60 \mathrm{~m}$ in the SOC) throughout. Two open boundaries are located a few kilometers up each strait. Thirty vertical s-levels are prescribed with non-linear stretching used to resolve the surface layer. Advection for momentum is integrated using a third-order upstream scheme (Shchepetkin and McWilliams 1998), while advection for tracers is integrated using a MPDATA family scheme (Margolin and Smolarkiewicz 1998). A very weak grid-size-dependent, harmonic form of the horizontal diffusivity is applied, while no horizontal viscosity is used (however, the thirdorder upstream advection scheme for momentum contains some implicit diffusion; Shchepetkin and McWilliams 1998). The pressure gradient term is solved by a density Jacobian with cubic polynomial fits (Shchepetkin and McWilliams 2003). Parameterization of the vertical mixing follows the generic length scale approach (Umlauf and Burchard 2003), with gen parameters coded in ROMS as described by Warner et al. (2005).

The atmospheric model COSMO-ME of the Italian Air Force National Meteorological Center (Centro Nazionale per la Meteorologia e Climatologia AeronauticaCNMCA) provides the surface forcing. COSMO-ME is the $7 \mathrm{~km}$ CNMCA operational setup of the non-hydrostatic regional model developed by the Consortium for SmallScale Modelling (COSMO) and based on Lokal Modell (Steppeler et al. 2003). COSMO-ME is initialized by the CNMCA 3D-VAR data assimilation system (Bonavita and Torrisi 2005) and driven by the ECMWF IFS boundary conditions (www.cosmo-model.org/content/tasks/operational/ usam/default.htm). This model provides net shortwave radiation, 10-m wind, 2-m temperature, relative humidity, total cloud cover, mean sea-level pressure, and total precipitation. Shortwave radiation forcing is directly provided by the COSMO-ME model, while the turbulent fluxes (momentum, heat, fresh water) are calculated interactively using ROMS sea surface temperature and COSMO-ME atmospheric data by applying the Coupled Ocean Atmosphere Response Experiment (COARE) algorithm (Fairall et al. 2003). The longwave radiation flux is estimated by a ROMS internal algorithm following a Berliand-family formula (Budyko 1974). The mean sea-level pressure is prescribed as a surface boundary condition in order to include the inverse barometric effect. The meteorological forcing time series is a sequential forecast using the forecast valid time $00+12 \mathrm{~h}-00+33 \mathrm{~h}$ from each forecast. COSMO-ME data were available with $3 \mathrm{~h}$ temporal resolution till December 2008, and $1 \mathrm{~h}$ in January and February 2009. Another meteorological model used in this experiment, although only for sensitivity testing, is the Coupled Ocean/Atmospheric Mesoscale Prediction System (COAMPS ${ }^{1}$ ) developed at the Naval Research Laboratory in Monterey, California (Hodur 1997). COAMPS was designed for use as a mesoscale atmospheric model in regional scales that can cover much of the continent of Europe using a horizontal resolution in the computational grid of about $27 \mathrm{~km}$. During the TSS trial period, two additional nests were run at $9 \mathrm{~km}$ and $3 \mathrm{~km}$ over the Sea of Marmara region.

Two main ocean model runs have been carried out: (1) TSS08 experiment initialized in late August 2008 that provided continuous integrations till early February 2009 and (2) TSS09 experiment initialized in early February 2009 and ran for 1 month. In both cases, outputs from a diagnostic run of 4 days are used as the initial model fields, with temperature and salinity held fixed in the diagnostic run in order to lower the spin-up time. Temperature and salinity fields used in the diagnostic runs come from CTD surveys of the NR/V Alliance on 30 August-1 September 2008 (TSS08 experiment) and 8-11 February 2009 (TSS09 experiment), respectively, with CTD data objectively mapped onto the model grid using a decorrelation scale of $20 \mathrm{~km}$ (comparable to the local internal Rossby Radius, $\sim 17 \mathrm{~km}$, estimated from the same CTD dataset).

As it will be discussed in Section 4.3, the TSS08 experiment shows, after 5 months of continuous integration, excessive diapycnal mixing. The model was therefore reinitialized with the CTD survey in early February (experiment TSS09) to overcome, at least partly, this inaccuracy. The TSS09 experiment is the run referred to throughout the paper when discussing model results for the period February-March 2009.

\footnotetext{
${ }^{1}$ COAMPS is a registered trademark of the Naval Research Laboratory.
} 
At the open boundaries located in the two straits, both of them several grid-cells wide, the model is nudged to match daily averages of $40 \mathrm{~h}$ low-pass filtered time series of vertical profiles of temperature, salinity, and current data collected continuously from early September till early February by the NRL-SSC moorings and bottom-mounted ADCPs (Jarosz et al. 2011). The nudging timescale is 3 days. Daily averages of 40-h low-pass filtered time series of vertically integrated volume transports, based on this very same dataset, are specified at the open boundaries using Flather boundary conditions (Flather 1976). Because of damage to the mooring located in the southern SOI, temperature and salinity data in the upper layer were not available; thus, climatological values were used. Moorings and ADCPs were recovered in early February 2009 for maintenance; thus, current and tracer data in February were only partially available. Because of the lack of actual measurements in February, the model in the TSS09 experiment was nudged to the average January conditions measured by the moorings and ADCPs, considered as a proxy for the wintertime behavior of the straits. Therefore, this is another difference between the TSS08 experiment and the TSS09 experiment. While in the former the boundary conditions are daily averages of actual measurements, in the latter, data used as boundary conditions are somewhat idealized.

For sensitivity tests, several additional realistic and semirealistic runs, described in the next sections, were performed. All experiments are listed in Table 1.

\section{Meteorological conditions}

Over the Mediterranean Sea region, significant cyclogenesis occurs, particularly in winter. Depressions usually move eastward. In the eastern Mediterranean Sea, some disturbances eventually move along a baroclinic corridor produced by thermal anomalies over the Aegean and Black Seas, with an axis oriented south-west/north-east, therefore directly impact- ing the Sea of Marmara region (Trigo et al. 1999; Karaca et al. 2000). Some other disturbances dissipate on the western Anatolian coastal area and other cyclones continue crossing Turkey eventually reaching the easternmost part of the Black Sea (Trigo et al. 1999, 2002; Karaca et al. 2000). During passages of cyclones in the cold season, prevailing winds are northeasterlies and to a lesser extent southwesterlies. In summer, northeasterlies blow most of the time (Alpar and Ÿuce 1998) and the number of cyclones passing over the region decreases significantly (Karaca et al. 2000).

According to COSMO-ME results (Fig. 2), the general winds (using the center grid point as representative) during the TSS period were winds from the northeastern quadrant and, secondarily, from the southwestern quadrant, which agrees with the known climatology. Monthly wind roses also clearly show differences in the wind fields between the September panel, a proxy for late-summer meteorological conditions with moderate but persistent northeasterlies, and the other, fall/winter, panels, when southwesterlies gain intensity due to the frequent passage of disturbances.

A comparison with meteorological buoy data (Fig. 3) shows fairly good agreement in magnitude, direction, and timing of the modeled winds over the Sea of Marmara. Model root-mean-squared errors, mean bias, and correlation coefficients of surface meteorological data are reported in Table 2, showing the general performance of the modeling system over the two sea-trial periods.

Heat fluxes estimated by ROMS using COSMO-ME surface fields are listed in Table 3. Cold outbreak events peaked in the late fall/early winter with a limited loss of heat in February 2009 , when the sea surface temperature of the Sea of Marmara usually reaches its lowest values (Beşiktepe et al. 1994). In February 2009, the heat loss was reduced also because of a persistent advection of southern warm air masses. Due to the limited size of the Sea of Marmara and generally weak gradients in sea surface temperature and surface meteorological fields, heat fluxes from the model are rather homogeneous over the basin (not shown).

Table 1 List of model simulations

\begin{tabular}{|c|c|c|c|c|c|}
\hline EXP label & Initial time & End time & Atmospheric forcing & Lateral boundaries & Initial field \\
\hline TSS08 & 30 Aug 08 & 11 Feb 09 & COSMO-ME & Open & Realistic \\
\hline ST08a & 30 Aug 08 & 01 Oct 08 & COAMPS & Open & Realistic \\
\hline ST08b & 30 Aug 08 & 01 Oct 08 & Wind-curl free COSMO-ME & Open & Realistic \\
\hline ST08c & 30 Aug 08 & 01 Oct 08 & No wind & Open & Realistic \\
\hline ST08d & 30 Aug 08 & 01 Oct 08 & COSMO-ME & Closed & Realistic \\
\hline ST08e & 30 Aug 08 & 01 Oct 08 & COSMO-ME & Closed & Homogeneous \\
\hline TSS09 & 11 Feb 09 & 10 Mar 09 & COSMO-ME & Open & Realistic \\
\hline ST09a & $11 \mathrm{Feb} 09$ & 10 Mar 09 & COSMO-ME & Closed & Realistic \\
\hline ST09b & 11 Feb 09 & 10 Mar 09 & COSMO-ME wind scaled to buoy & Open & Realistic \\
\hline
\end{tabular}



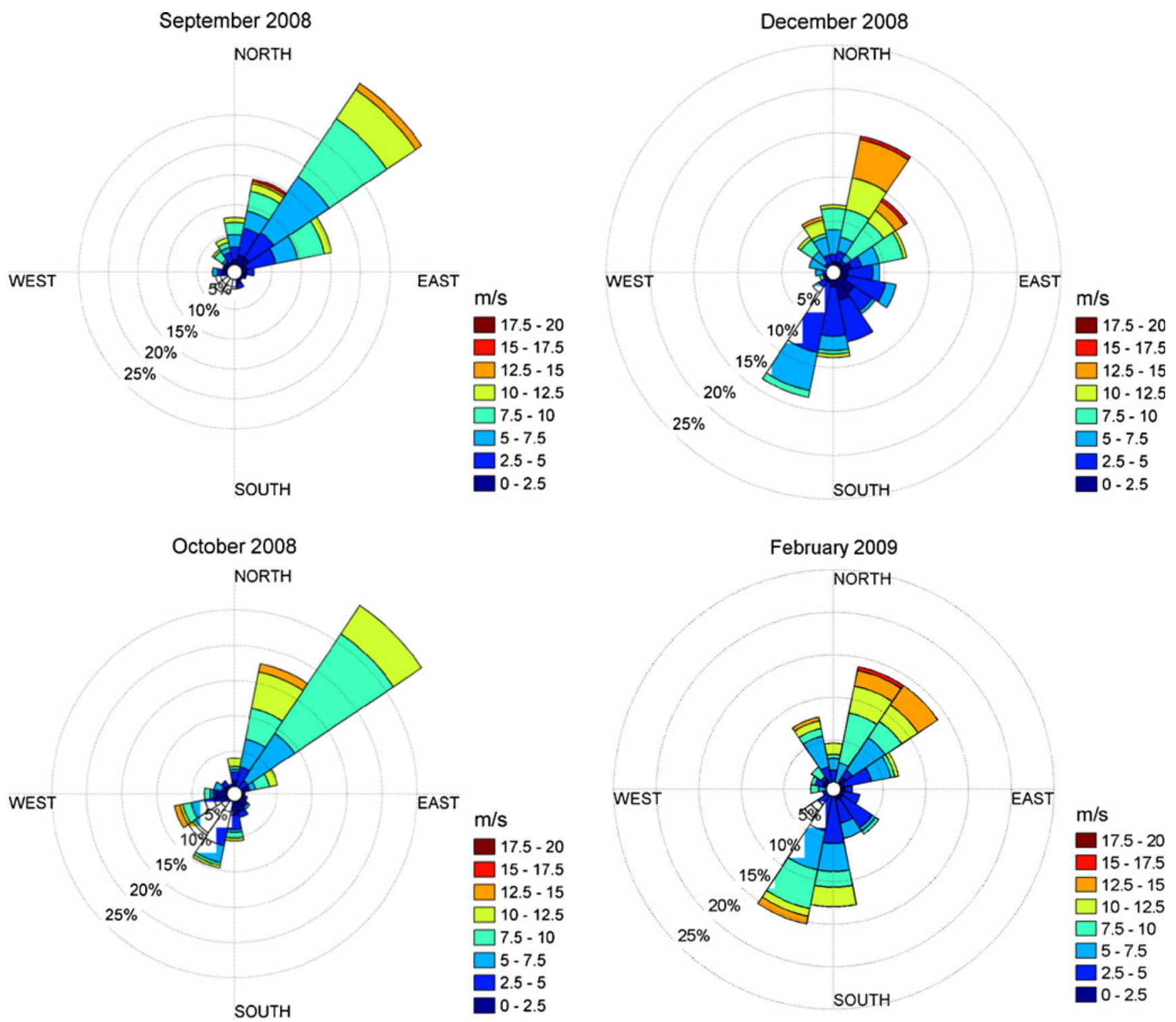

Fig. 2 Monthly wind roses from the central grid point of the meteorological model COSMO-ME

\section{Results}

\subsection{General circulation}

Monthly mean circulations of the Sea of Marmara surface waters are presented in Fig. 4. The general surface circulation of the Sea of Marmara consists of quasipersistent features and small mesoscale, transient eddies. The flow exiting the SOI is well defined and it is usually directed southward towards the Bozburun Peninsula; then, it turns southwestward and later northwestward, pointing to the northern coast. Eventually, it leaves the Marmara region entering the SOC. This meandering current and its characteristic variability was a persistent feature in the model simulations discussed here (Fig. 4). In addition to the meandering current, a large anticyclonic eddy occupied the central part of the basin in the simulations. The eddy in the model is better defined in September 2008 and February 2009 than in other months (October and December) when its footprint is smaller and weaker, being confined to the northeastern part of the sea and often merged with a weaker anticyclonic eddy typically found to the west of the SOI exit. According to the model simulations, an additional small anticyclonic eddy was present in the northwestern part of the basin during October and December and attached to the northern coast in September. Surrounding the meandering flow and the large anticyclonic eddy, there are several small mesoscale cyclonic eddies with size $(\sim 30 \mathrm{~km}$ or smaller) comparable to the internal Rossby radius of deformation. Cyclonic eddies are found in particular along the southeastern shelf, north of Marmara Island 
Fig. 3 Wind-barbs plots from (top to bottom): the meteorological buoy during TSS08, COSMO-ME model during TSS08, the meteorological buoy during TSS09, and COSMOME model during TSS09. COSMO-ME model data during TSS0 8 are available every $3 \mathrm{~h}$, while during TSS09 every hour. Meteorological buoy data have been low-pass filtered with a 2-h cutoff frequency and then sub-sampled at $1 \mathrm{~h}$ for enhanced readability
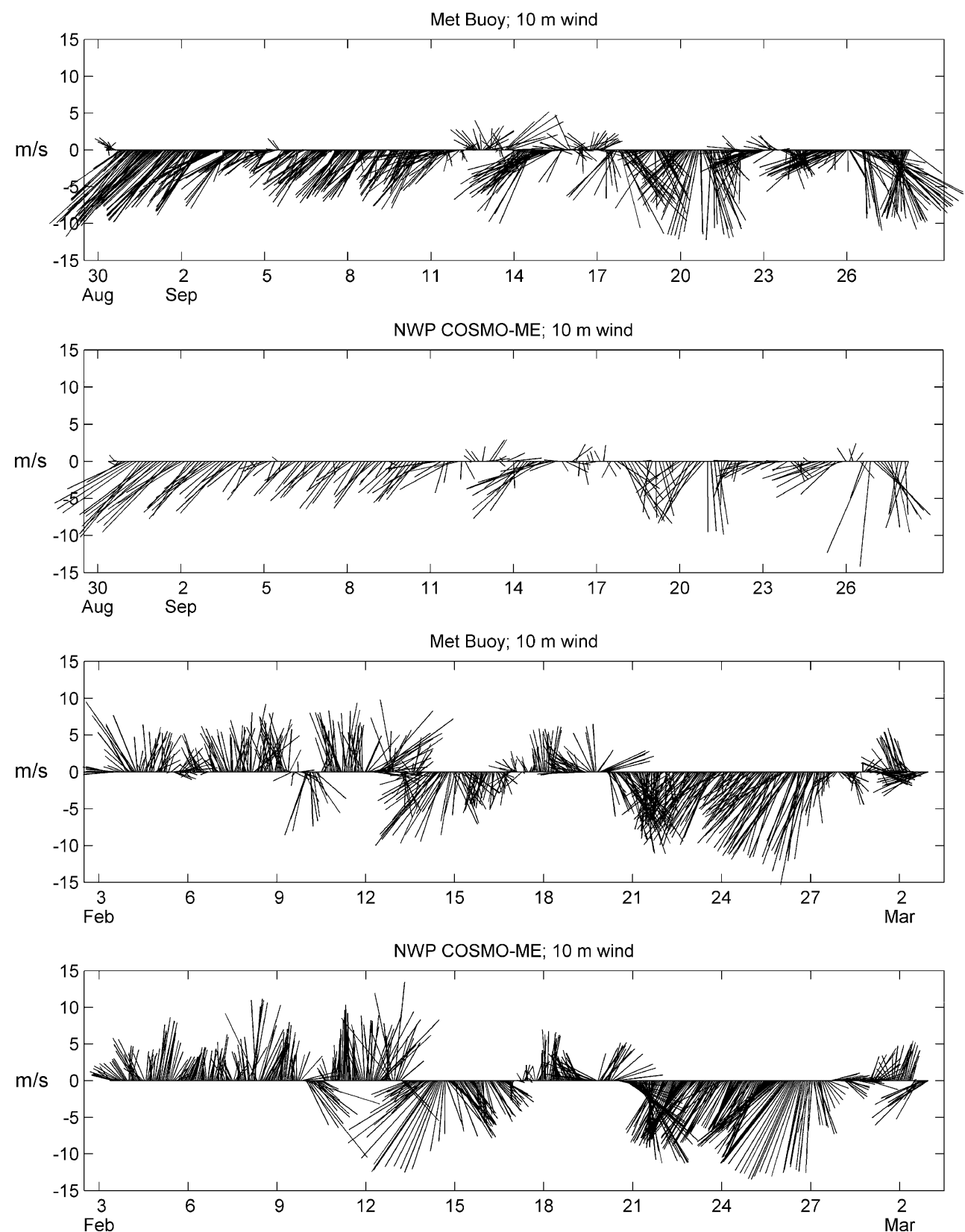

and in Erdek Bay. These model simulations show small scale eddies, weather cyclonic or anticyclonic, which are mostly transient features with a general weak signal on the monthly mean field.

It should be noted that the seasonal variability of the circulation cannot be resolved by these numerical experiments since one of the major forcings of the system, the SOI flow, does have a seasonal cycle that peaks in spring-early summer, which is outside the time window covered by the simulations. In fall-winter, the net transport is generally weaker (Beșiktepe et al. 1994); during the TSS08 simulation, the average net transport toward the Marmara Sea, applied as boundary condition, was $110 \mathrm{~km}^{3} /$ year.
4.2 Roles of meteorological, boundary condition, and initial condition forcing

A set of sensitivity experiments was designed to investigate the role of the different forcing factors on the circulation of the Sea of Marmara: meteorological forcing, outflow/inflow conditions, and initial conditions. This set of numerical experiments was focused on the September 2008 cruise trial period (TSS08).

The first departure, ST08a ("ST" is the acronym for Sensitivity Test, Fig. 5b), from the TSS08 run (considered here as the "control" run, Fig. 5a) was carried out using realistic COAMPS meteorological forcing instead of COSMO-ME forcing. A visual comparison between these 
Table 2 Scores of the modeling system versus buoy measurements: mean bias (mb, model minus observations), root-mean-squared error (rmse), correlation coefficient (corr)

\begin{tabular}{|c|c|c|c|c|c|c|}
\hline & \multicolumn{3}{|l|}{ TSS08 } & \multicolumn{3}{|l|}{ TSS09 } \\
\hline & $\mathrm{mb}$ & rmse & corr & $\mathrm{mb}$ & rmse & corr \\
\hline Sea-level pressure & -0.24 & 1.14 & 0.95 & 0.86 & 1.30 & 0.99 \\
\hline Air temperature $2 \mathrm{~m}$ & -0.30 & 1.00 & 0.95 & -0.61 & 1.34 & 0.94 \\
\hline Relative humidity & -0.13 & 6.51 & 0.74 & 2.37 & 7.90 & 0.48 \\
\hline Wind speed $10 \mathrm{~m}$ & -0.59 & 1.87 & 0.72 & -0.62 & 2.27 & 0.81 \\
\hline Latent heat flux & $\mathrm{n} / \mathrm{a}$ & $\mathrm{n} / \mathrm{a}$ & $\mathrm{n} / \mathrm{a}$ & -1.92 & 20.3 & 0.92 \\
\hline Sensible heat flux & $\mathrm{n} / \mathrm{a}$ & $\mathrm{n} / \mathrm{a}$ & $\mathrm{n} / \mathrm{a}$ & 5.82 & 19.4 & 0.91 \\
\hline
\end{tabular}

Units for mean bias and root mean squared error are $\mathrm{mb}$ (sea-level pressure), ${ }^{\circ} \mathrm{C}$ (air temperature), \% (relative humidity), $\mathrm{m} / \mathrm{s}$ (wind speed), and $\mathrm{W} / \mathrm{m}^{2}$ for latent and sensible heat fluxes. Latent and sensible heat fluxes from the buoy, as well as wind at $10 \mathrm{~m}$, are post-processed quantities using Fairall et al. (2003) algorithm. Because of a failure of the sea-surface temperature sensor during TSS08, latent and sensible heat fluxes are not available and wind speed at $10 \mathrm{~m}$ was estimated by using a simpler bulk formula with a neutral stability assumption (original height of the sensor $=2.5 \mathrm{~m}$ above the sea surface)

two experiments clearly shows the wind's impact on the strength and size of the main anticyclonic eddy and other cyclonic mesoscale features. The general picture is conserved, yet the differences in the modeled size and strength of these eddies show a general sensitivity of these features to the meteorological forcing since, on average, the two forcings are similar in their wind fields (see Fig. 6 and Table 3) and heat fluxes (see Table 3).

The monthly averaged wind curl field (Fig. 6) resembles the footprint of the dominant northeasterly winds, with limited variation offshore and a deceleration in the areas of significant orography (shown in Fig. 1). This wind curl structure leads to a SE-NW cross-basin gradient, locally producing or enhancing cyclonic and anticyclonic vorticities on the left and right sides (looking downwind), respectively. In order to test the role of the wind curl, in the ST08b experiment (Fig. 5c), the COSMO-ME center grid wind value is used for the whole domain, pretending to have a spatially homogenous (i.e., curl free) but variable with time wind forcing. The resulting ROMS surface boundary condition is not exactly curl free due to atmospheric stability dependence on the ocean model sea surface temperature (SST), but the momentum stress curl (not shown) is about two orders of magnitude smaller than the curl from the TSS08 run. The results clearly demonstrate the role of the wind-stress curl in determining the circulation of the Sea of Marmara. Specifically, compared to the control run (Fig. 5a), the main anticyclonic eddy is much weaker and is attached to the northern coast, and the cyclonic eddy in the southeastern shelf is no longer present.

When the ocean model is run without any wind forcing at all (for the ST08c experiment the wind speed is set to zero), the influence of the SOI outflow can be seen (Fig. 5d). An anticyclonic tendency imprinted by the injection of light Black Sea waters in the Marmara basin results in an energetic anticyclonic eddy attached to the SOI exit. The lack of such an energetic eddy in Fig. 5c indicates that the northeasterly wind stress and its time variation, rather than its curl, plays an important role in suppressing the formation of such a feature.
Table 3 Monthly values of basin-averaged heat fluxes $\left(\mathrm{W} / \mathrm{m}^{2}\right)$, mean wind speed $(\mathrm{m} / \mathrm{s})$, directional mean wind speed $(\mathrm{m} / \mathrm{s})$, and wind curl $(\mathrm{m} / \mathrm{s}$ over $100 \mathrm{~km})$ for TSS08 experiment (COSMO-ME meteorolog- ical forcing), TSS09 (COSMO-ME meteorological forcing), and ST08a (COAMPS meteorological forcing)

\begin{tabular}{llcccr}
\hline & Month & Heat flux & Mean wind speed & Directional mean wind speed & Wind curl \\
\hline TSS08 & Sep 08 & -48 & 4.93 & 3.65 & 0.21 \\
& Oct 08 & -54 & 5.10 & 2.17 & -0.21 \\
& Nov 08 & -90 & 4.99 & 1.77 & 0.35 \\
& Dec 08 & -126 & 4.76 & 1.55 & 0.36 \\
TSS09 & Jan 09 & -68 & 4.41 & 1.09 & 0.48 \\
ST08a & 11 Feb 10 Mar 09 & -31 & 5.12 & 3.42 \\
\hline
\end{tabular}

The mean wind speed does not take into account the direction (i.e., opposite winds do not cancel out), while the directional mean does take directions into account 
Fig. 4 Monthly mean surface circulation and sea level anomaly for September (a), October (b), December (c) 2008 and 11 February-10 March 2009 (d). The first three panels are from the TSS08 numerical experiment, while the last panel is from the TSS09 numerical experiment
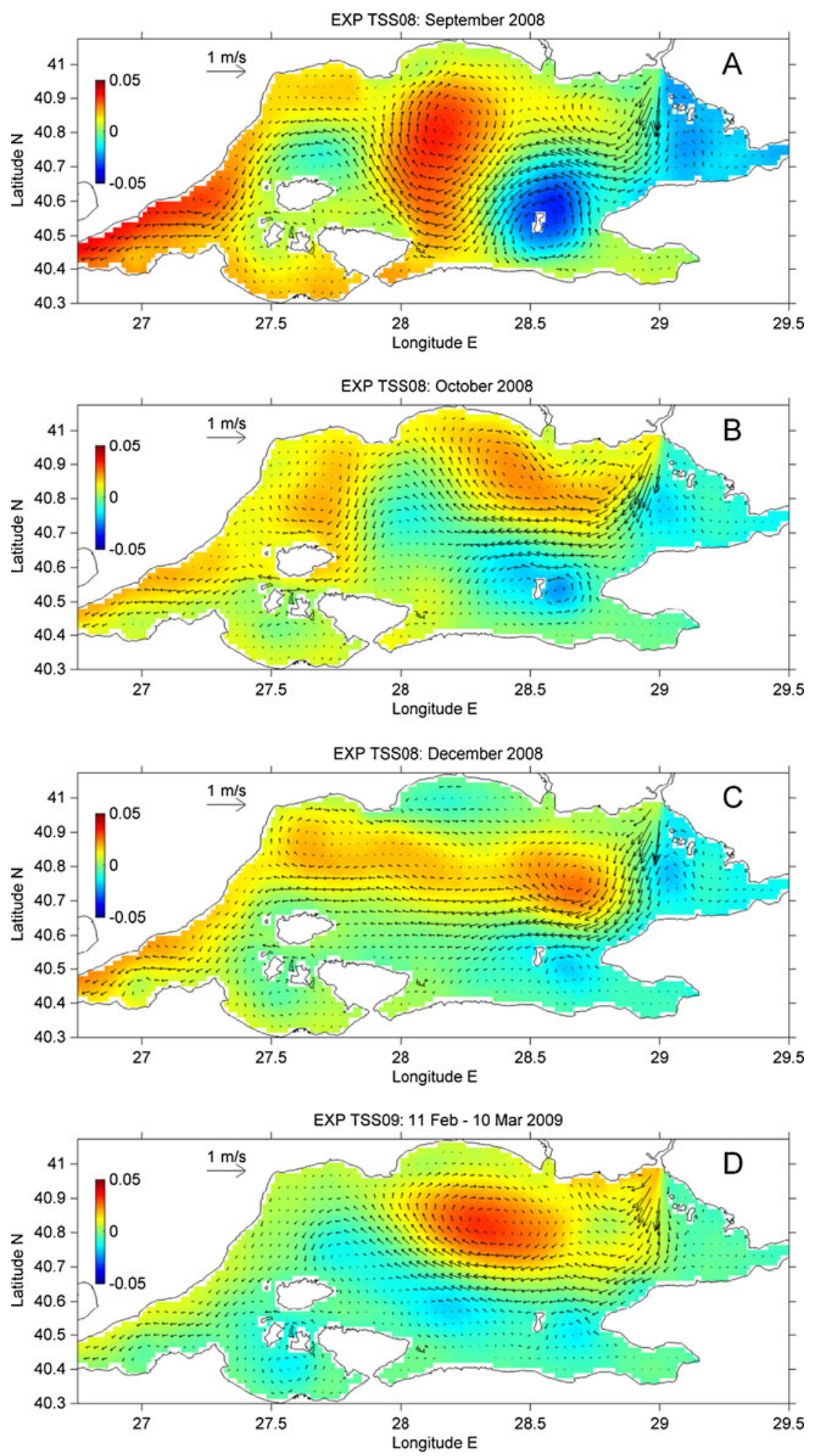

In order to further investigate the role of lateral forcing, an experiment (ST08d, Fig. 7b) was carried out with COSMOME meteorological forcing and closed lateral boundaries (i.e., no flow from/to the straits). The main anticyclonic eddy is still present and is stronger than in the case with lateral forcing. The two separate cyclonic eddies to the east and southwest of the SOI in Fig. 7a have now merged into a larger and stronger cyclone just south of the (blocked) SOI. Arguably, in this experiment, there is still memory of the strait outflow/inflow through the initial density field (model initial conditions). If a horizontally homogeneous two-layer idealized initial field is used instead (ST08e, Fig. 7c), the results are similar; 
Fig. 5 Monthly mean surface circulation and sea-level anomaly for September 2008 from experiments TSS08 (a, same as panel a of Fig. 4), ST08a (b), ST08b (c), and ST08c (d). See Table 1 for the differences in experimental setups for these cases
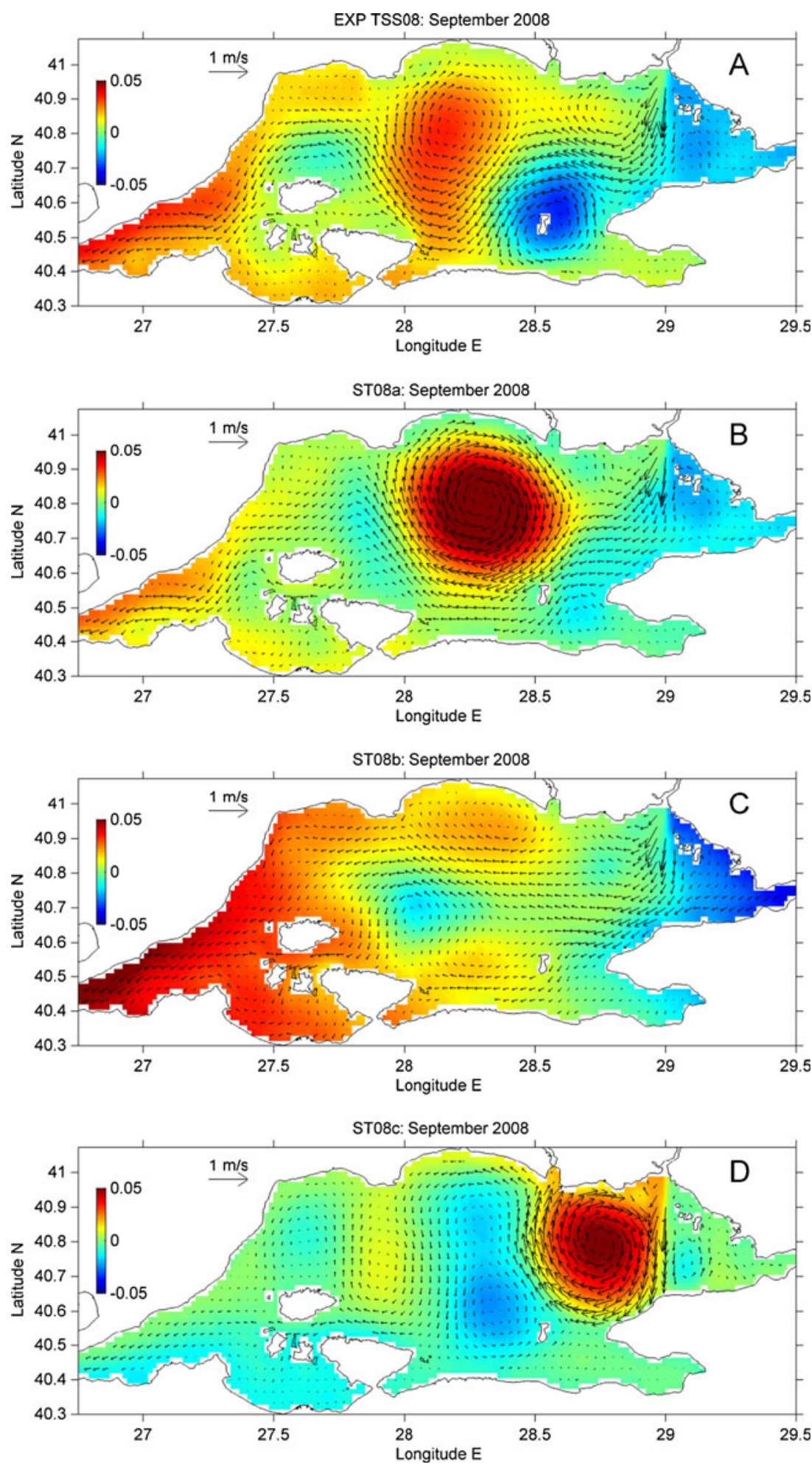

however, the main anticyclonic eddy is now weakened and the large cyclonic eddy from Fig. $7 \mathrm{~b}$ has dispersed into several weaker cyclones to the east and southeast of the SOI (Fig. 7c).

Summarizing these results, the main anticyclone eddy was present in all the experiments with northeasterly associated wind curl (including ST08e with only wind and homogeneous two-layer initial conditions) and absent or greatly changed in the two experiments without it. In contrast, the circulation directly to the west of the SOI seems to be sensitive to all varieties of forcing as the solutions are opposite to each other for the case with no 
Fig. 6 Monthly mean wind speed and mean wind curl for September 2008 from COSMOME model output (upper panels) and COAMPS model output (lower panels)
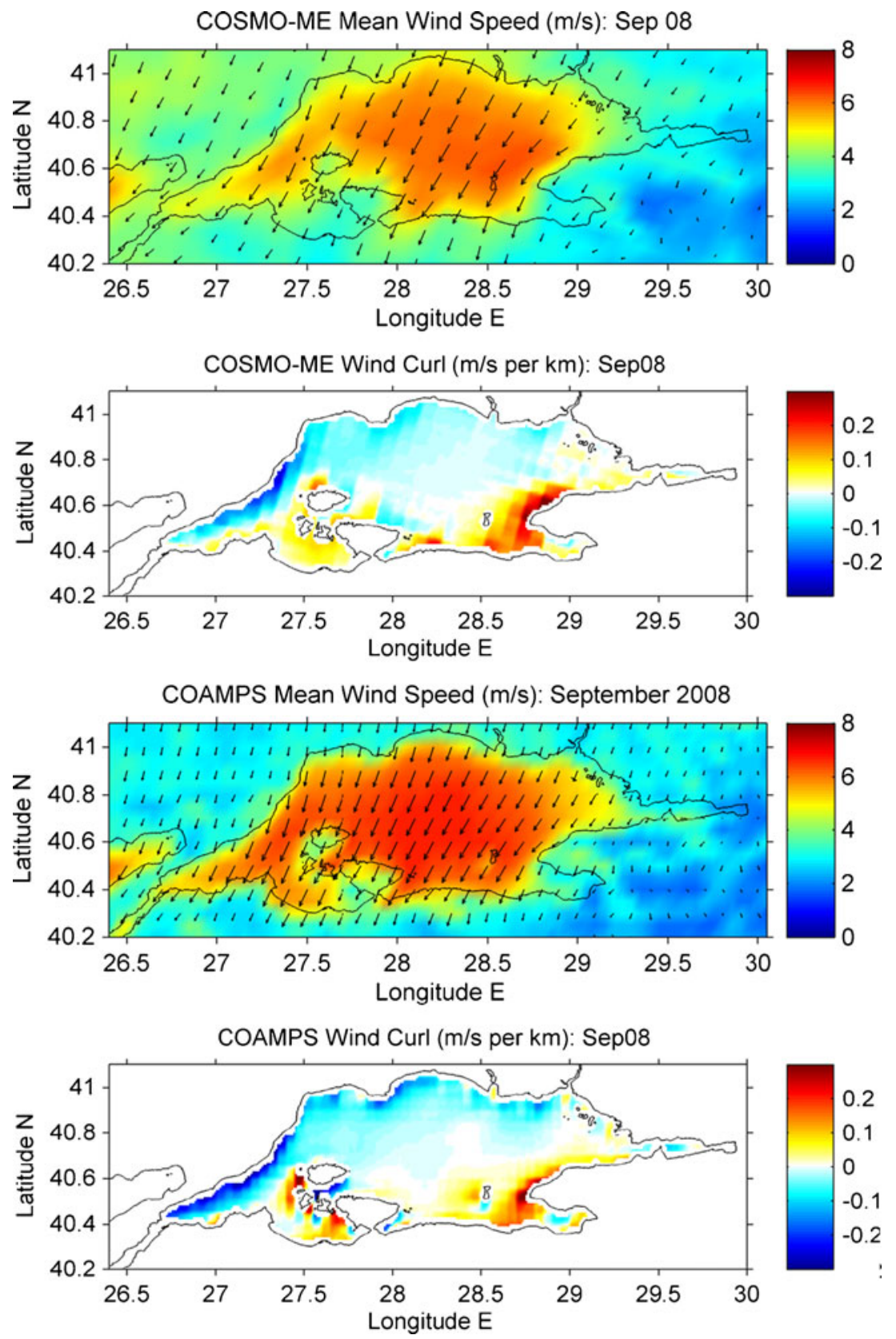

wind compared to the case with no outflow/inflow, and even differ significantly between the two cases with no outflow/inflow and different initial conditions.

\subsection{Considerations on model performance}

The general picture depicted by these simulations (Fig. 4) agrees with the knowledge about the circulation described by Beşiktepe et al. (1994). However, the sketch provided by Beșiktepe et al. (1994) in their figure 34 is by necessity simplified since the circulation does have high mesoscale and sub-mesoscale variability superimposed on these quasipermanent features, and the nature of such variability does not lend itself to representation by schematics. Comparisons between our monthly averaged model results and observational data pose similar difficulties as the mesoscale variability of the model will mostly be averaged away and the data generally provide only "snapshots" of the circulation. Regardless of averaging, exact agreement with the observed mesoscale is not expected from the model due (among other reasons) to the smoothed boundary forcing used for the model. Nevertheless, it is useful to compare the model simulations to any available observations to try and learn as much as possible about the model's performance.

To start, the model results from the TSS08 experiment were compared to observations collected during a CTD 
Fig. 7 Monthly mean surface circulation and sea-level anomaly for September 2008 from experiments TSS08 (a, same as panel a of Fig. 4), ST08d (b), and ST08e (c)
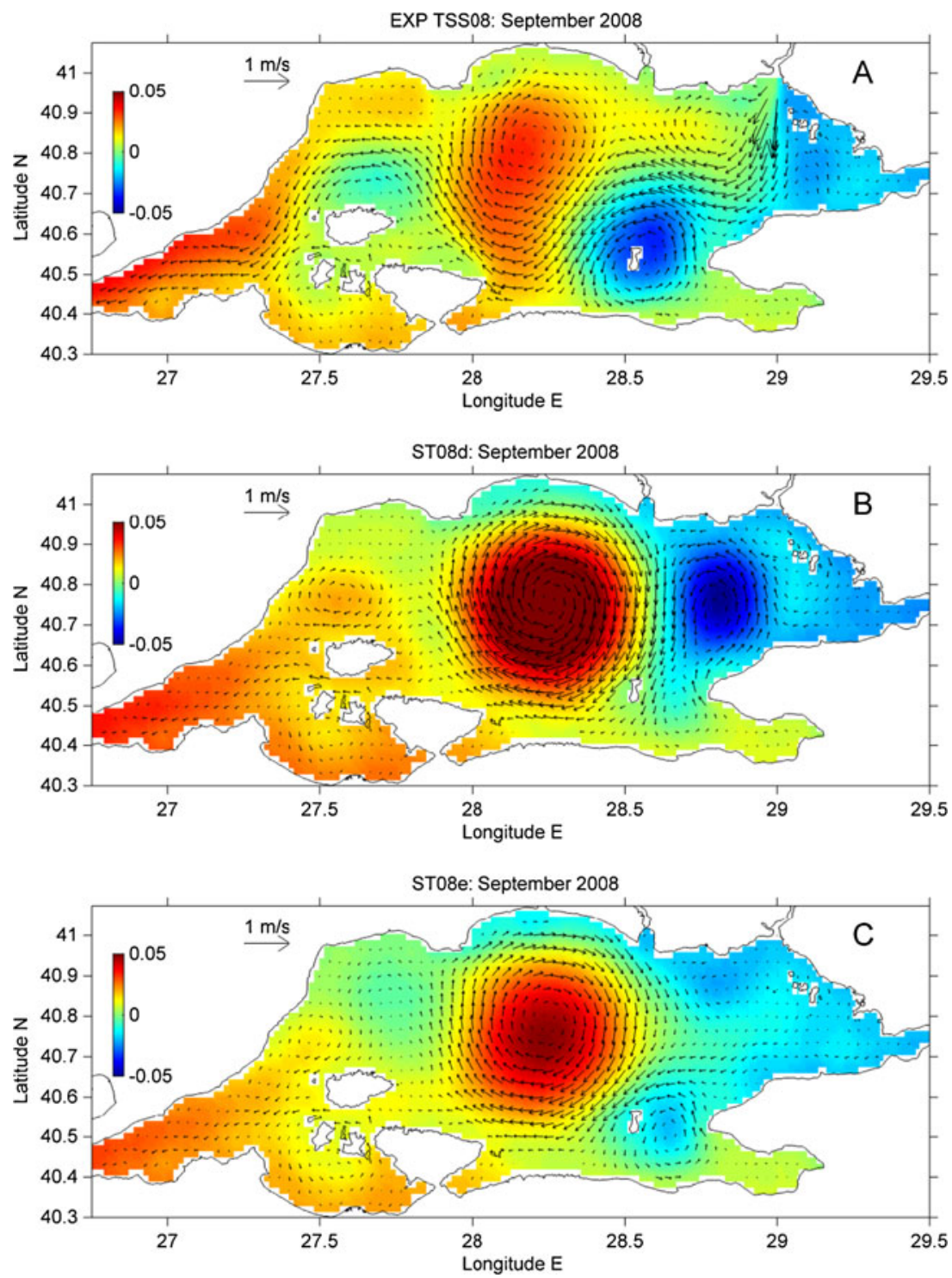

survey conducted from 8 to 11 September 2008 and to a concurrent full basin-wide multi channel sea-surface temperature (SST) image on 11 September, 2008, derived from the Advanced Very High Resolution Radiometer (AVHRR) onboard NOAA-17 satellite. Temperature and salinity data from the CTD survey have been optimally interpolated using a decorrelation length scale of $20 \mathrm{~km}$. Assuming geostrophy and a level of no motion at $100 \mathrm{~m}$ depth (Beșiktepe et al. 1994), the dynamic height anomaly (DHA) was computed and then compared to the sea-level anomaly from the model (Fig. 8). The DHA suggests the existence of a large anticyclone in the central part of the basin with some weaker cyclonic footprints around it. ROMS sea-level anomaly consistently shows a large anticyclonic eddy in the central part of the basin, although the location is not exactly coincident with the location from the DHA map. Smaller cyclonic eddies in ROMS are also stronger and in different locations than the cyclonic features seen in the
DHA observations. Differences near the SOI in these maps are suggestive of an overestimation of inflow from this strait, but since the inflow of the model is primarily determined by ADCP measurements, this further suggests that the model may not be mixing or dispersing the inflowing plume properly. The strength of the cyclone to the east in the model can also be ascribed, at least partly, to the meteorological forcing (as can be deduced by the comparison between Fig. 5a, b).

Similar conclusions can be drawn from the SST comparison (Fig. 9). In the AVHRR SST map, a core of warmer water is located in the center of the observed large anticyclonic eddy. Around the large eddy, a band of colder waters is found. Both features are represented by the model solution, as well as the existence of a broad band of warmer waters on the western side of the basin. Although the broad details of the SST structure are consistent between the model and the observations, there are also clear differences 
Fig. 8 Contours of dynamic height anomaly $(\mathrm{cm})$ computed from CTD data collected between 8 and 11 September 2008 (upper panel) and sea-level anomaly $(\mathrm{cm})$ from the numerical model (TSS08 experiment, lower panel)
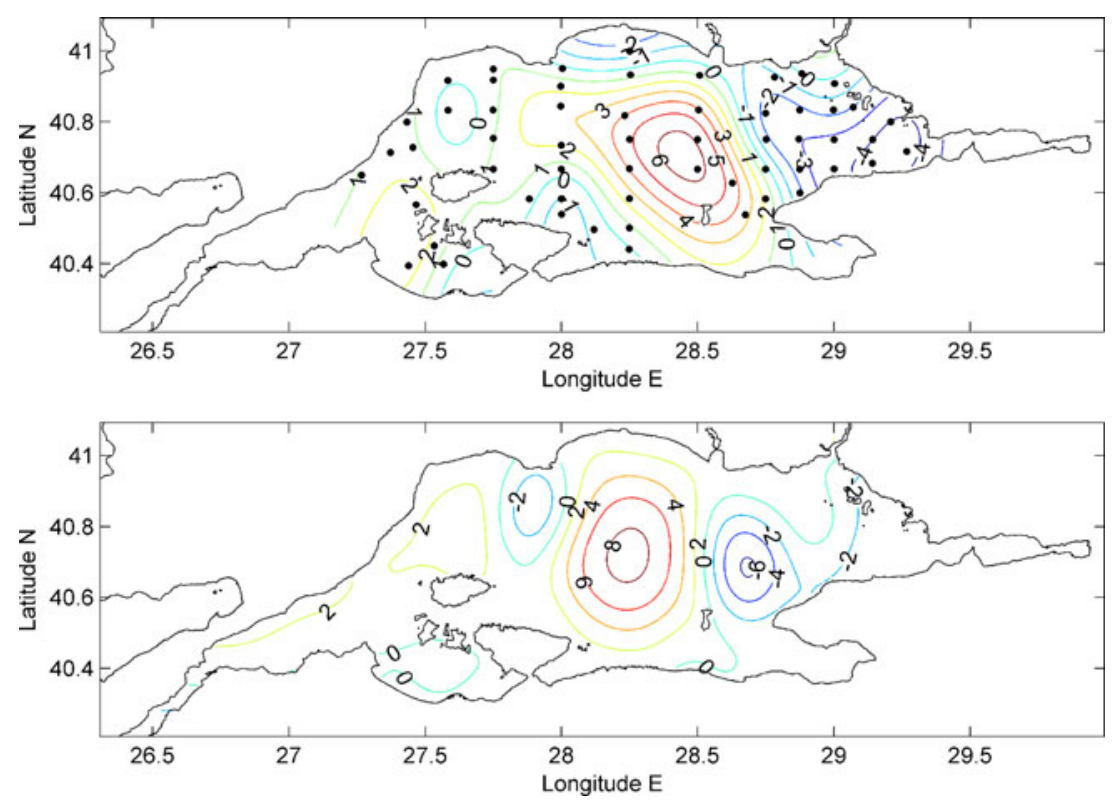

in the mesoscale and smaller scale features as the westward shift of the warm core associated to the anticyclone (as it was shown in Fig. 8) and the large cold pool in the SOI area.

The next major CTD survey was carried out in early February 2009. This survey is used to assess model performance after 5 months of continuous integration without any data assimilation. Root-mean-squared errors between model and observations at each CTD location are shown both for temperature and salinity in Fig. 10. Errors are depth averaged over each CTD profile down to a depth of $50 \mathrm{~m}$ since most of the discrepancies are located in the upper layer (this can be clearly seen from Fig. 11, discussed later). Largest errors are found in the proximity of the SOI exit. This is somewhat expected; the boundary conditions for temperature and salinity in the upper layer of the SOI
Fig. 9 Multi-channel SST map from AVHRR onboard NOAA17 (upper panel, in degrees Celsius) along with ROMS SST (TSS08 experiment) corresponding snapshot (lower panel, in degrees Celsius)

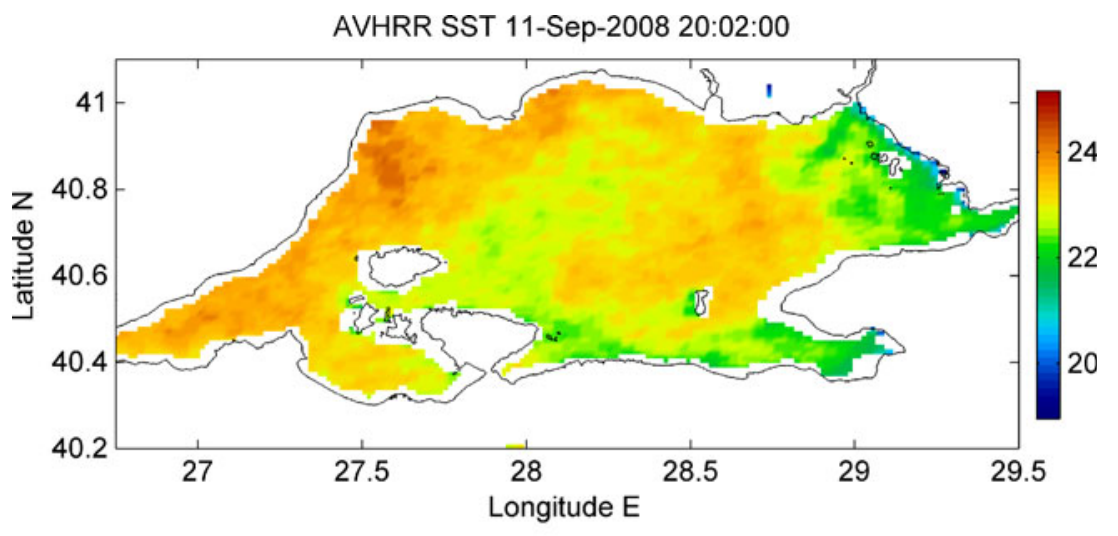

ROMS SST 11-Sep-2008 21:00:00

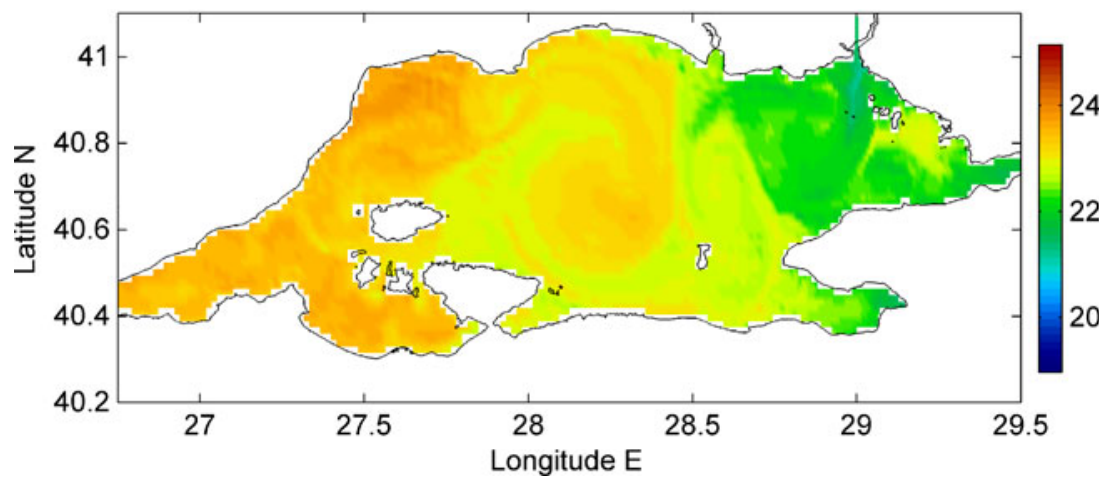


Fig. 10 Root-mean-squared errors between model (experiment TSS08) and CTD profiles for temperature (upper panel) and salinity (lower panel). CTD data were collected on 9-13 February 2009. The mean is taken over depths down to $50 \mathrm{~m}$
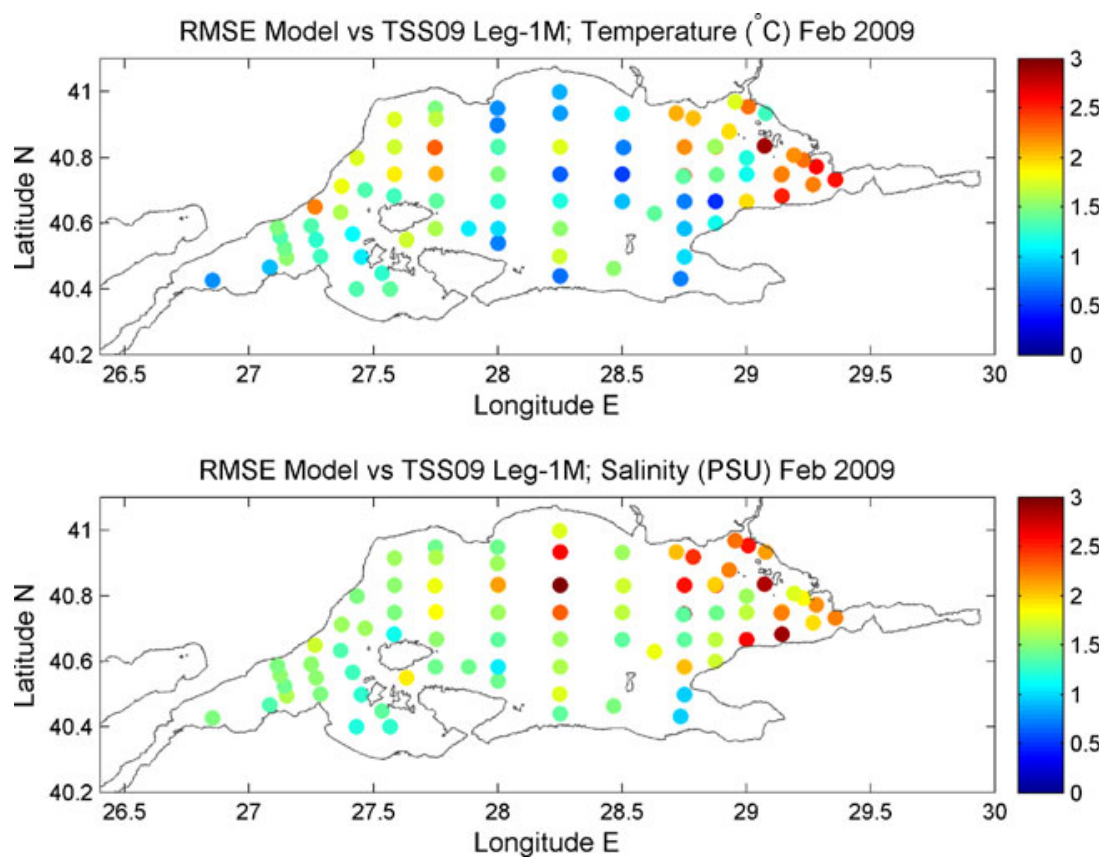

were taken from a climatological database because of the damaged mooring. Additionally, the representation of the strait outflow contains several uncertainties, and this model application is not meant to resolve the strait dynamics. Therefore, limited skills in the area are understandable. Higher errors on temperature are also found in the northwestern part (see Fig. 10), where the model is warmer compared to the observations (not shown), and higher errors on salinity are also found in the central part (see Fig. 10), where the salinity in the model is lower (not shown). The reason for this is that the anticyclone developed in the model in the later part of the TSS08 experiments was likely too strong, and this feature entrains low salinity waters from the SOI in the central part and limits the export of cold waters toward the SOC.

The mean profile of CTD/model pairs shown in Fig. 11 highlights the vertical extension of the errors. Both the thermocline and halocline in the model are not sharp enough when compared to the observations. Some reasons for this discrepancy might be spurious diapycnal mixing due to the terrain-following coordinates of the model and/or spurious mixing due to the applied vertical mixing scheme.
Fig. 11 Mean CTD and corresponding model (experiment TSS08) temperature and salinity profiles. CTD stations included in these averages are the same as for Fig. 10
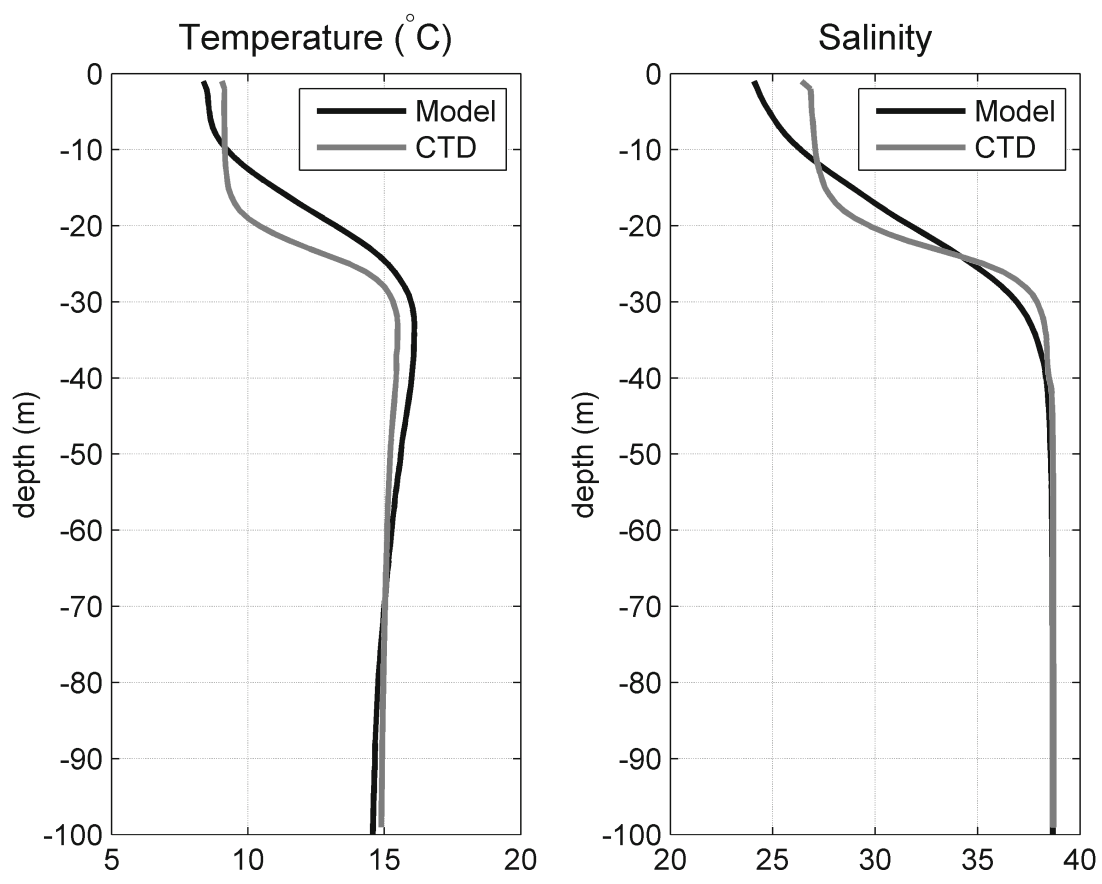
Both the observations and the model show a temperature maximum located just below the thermocline (Fig. 11). This maximum is likely an imprint of Aegean waters that are not dense enough to sink below the pycnocline after entering the Sea of Marmara from the SOC (Beşiktepe et al. 1993). In the model, however, the signal of the warm pool is larger and much broader than in the observations. The time series of sea-surface temperature from the model seems consistent with the variations observed from AVHRR SST map (Fig. 12), suggesting a fairly good representation of the heat fluxes. However, a comparison between ROMS results and NRL mooring current data in the southern SOI (Fig. 13) shows an underestimation of the flow speed in the lower layer, suggesting that the model has too weak of an advective heat transport in the lower layer to the Black Sea (i.e., outside of the domain), and that could be the reason for the larger warm pool found in the model.

4.4 Response to a severe windstorm: the case of February 2009

This section is focused on a storm characterized by strong northeasterlies that passed over the region in late February 2009 (Fig. 3). Analysis of this event leads to a better understanding of the response of the Sea of Marmara to a gale-force wind (winds up to $18 \mathrm{~m} / \mathrm{s}$ ), which is a typical atmospheric event that occurs in this geographical area. A release of several surface Lagrangian CODE drifters was scheduled for the night/morning of 21 February, and all available drifters were deployed just before the arrival of

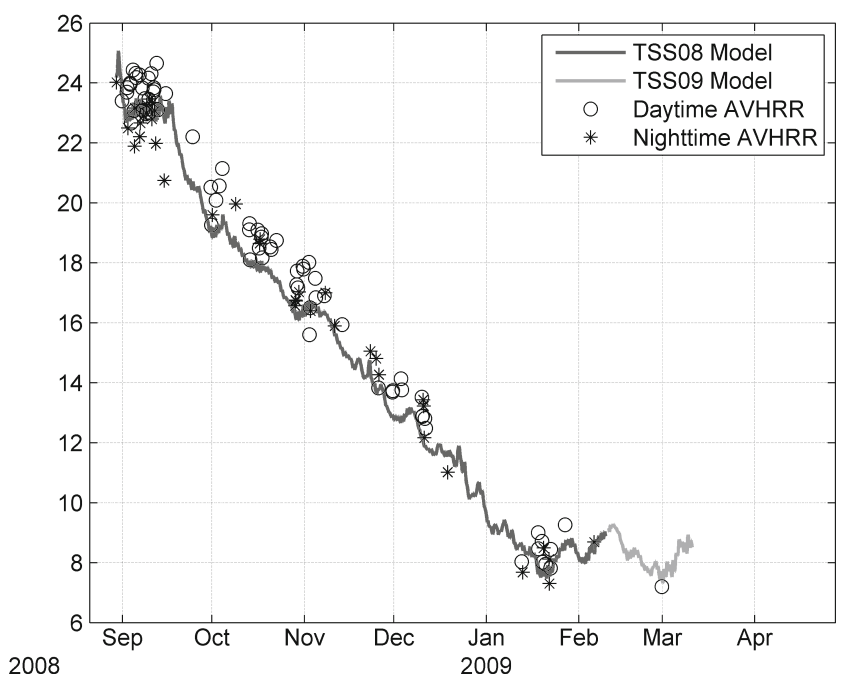

Fig. 12 Time series of basin-averaged model SST (dark gray line from TSS08 experiment, light gray from TSS09 experiment) and basin averaged SST from AVHRR images with at least $80 \%$ coverage of the basin. Night-time passes are from $8 \mathrm{PM}$ till $8 \mathrm{AM}$ and day-time passes from 8AM till 8PM UTC the storm. Figure 14 shows the drifter tracks during the time period of the storm (21-28 February 2009). Four drifters released near the SOI exit were captured by the outflow and traveled southwestward and then westward. Three other drifters, released on the western side of the SOI outflow, were clearly trapped in a local anticyclonic eddy and did not follow the pathway of the drifters released on the eastern side of the outflow. Drifters released in the central part of the Sea of Marmara generally traveled westward. Westward flow seemed especially dominant during the second half of the storm (February 25-27). At the end of the storm (the afternoon of February 27), the drifter observations imply that there was a prompt relaxation of the surface circulation with a reversal of flow along the northern coastline towards the east.

The corresponding model solution from the TSS09 experiment (that is, the run initialized in early February) is shown in Fig. 15. The upper panel shows circulation and temperature during the strongest part of the storm (February 26). Currents and temperature for the spin-down period (February 27-28) are shown in the middle panel. The features shown by the model are consistent with those shown by the drifter observations in Fig. 14: the basin-wide westward flow, the southwestward outflow from the SOI, and a weak recirculation region to the west of the strait exit are all present in the model. There is also a noticeable upwelling event of warm salty waters in the model, marked by the sea-surface temperature front on the southeastern side of the sea. As the storm spins down, there is a prompt relaxation of the surface circulation with a return flow along the northern coast and an anticyclone now extending all the way to the eastern coast (as suggested also by the actual Lagrangian drifter trajectories). This model circulation pushes back the front of the warm upwelled waters. A trace of the warm waters remains, but confined to the southeastern shelf region, where a cyclone is found. The cyclone was also present during the strongest part of the storm, but has now grown and shifted westward as the wind relaxed.

A direct comparison with the only AVHRR SST map (Fig. 15c) available for the storm period (the sky was overcast throughout the full storm) does not provide clear supporting evidence of the existence of the temperature front. Lack of the temperature front in the image could be explained by the fact that the snapshot was taken during the spin-down period when the front is already much reduced in size in the model as well and the remnants of the front could be partially masked by the cloud cover over the southern coastal area. However, in general, the features depicted by the corresponding snapshot from the model (Fig. 15b) are fairly consistent with the AVHRR SST map; the warm water footprint of the large anticyclone can be clearly seen, along with a cold filament in the west-central 
Fig. 13 Time series of along-strait currents $(\mathrm{m} / \mathrm{s})$ from experiment TSS08 (upper panel) and the ADCP located in the main channel of the southern entrance of the Strait of Istanbul (lower panel). Positive flow is towards the Black Sea and negative flow is towards the Marmara Sea
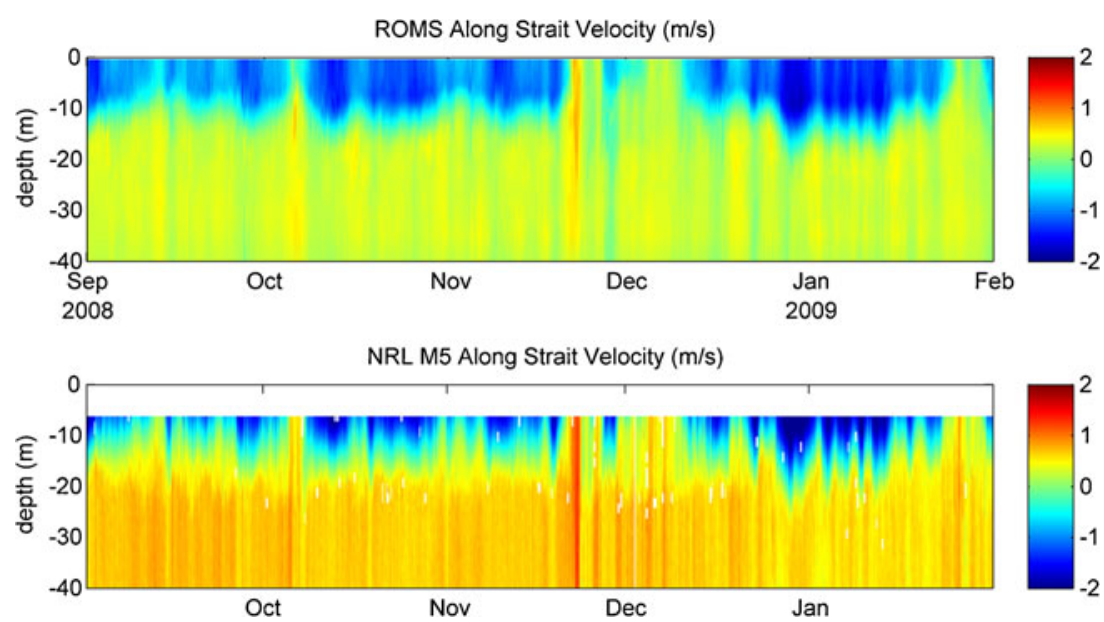

portion of the basin and a small-scale warm core in the same general location as the model cyclone along the southern coastal area.

\subsection{Pycnocline displacement}

Deep, land-locked seas with limited exchange to the broader ocean, such as is the case for the Sea of Marmara, are well known to exhibit frequent and sustained pycnocline displacements in response to wind forcing (e.g., Csanady 1982). One mechanism for this is the Ekman transport induced upwelling or downwelling. The average depth of the Sea of Marmara is $\sim 300 \mathrm{~m}$ and the average depth of the surface layer is $\sim 25 \mathrm{~m}$. Thus, this sea may be approximated as a 1.5 layer reduced gravity case. The efolding scale of the pycnocline displacement from the coast is the internal radius of deformation $R$, which for this sea is $\sim 17 \mathrm{~km}$. Considering the shape of the Marmara basin and its limited meridional extension ( $\max .70 \mathrm{~km}$ ), a large part of the basin falls into a distance from the coast shorter than $R$. The length of the basin in the northeast-southwest direction (that is, along the direction of the dominant winds) is several times longer than $R$, but the basin width along the cross-wind direction is only three to four times $R$.
In the case of a narrow basin, upwelling and downwelling can even happen simultaneously on opposite coasts and interfere with each other. Cushman-Roisin et al. (1994) show that upwelling is significantly inhibited in basins of width less than $2 R$ due to interference from downwelling on the opposite coast. Since the Sea of Marmara exceeds but comes close to this threshold, upwelling should not be significantly inhibited except in the narrower parts of the basin. For analyses of wind-generated upwelling/downwelling, a critical parameter is the wind impulse (see Csanady 1977; Cushman-Roisin et al. 1994; and references therein).

A remarkable example of pycnocline variations in response to the wind can be seen in Fig. 16 which shows salinity observations during February 2009 from the SEPTR (Shallow-water Environmental Profiler in Trawlresistant Real-time configuration) mooring deployed on the western side of the Sea of Marmara (Fig. 1). The variability of the halocline depth (an appropriate representation of the pycnocline depth because salinity controls the density field in the Sea of Marmara) should be interpreted as the response of the internal mode of the basin given that the sea can be adequately approximated as a 1.5 layer system. During the storm in late February, the maximum depth of the halocline was $40 \mathrm{~m}$, which is a displacement of roughly
Fig. 14 Surface Lagrangian drifters trajectories (upper panel) during 21-28 February. The color code is time. Circles mark drifter deployment locations and $x$ 's mark drifter positions at the end of February 28 or upon failure

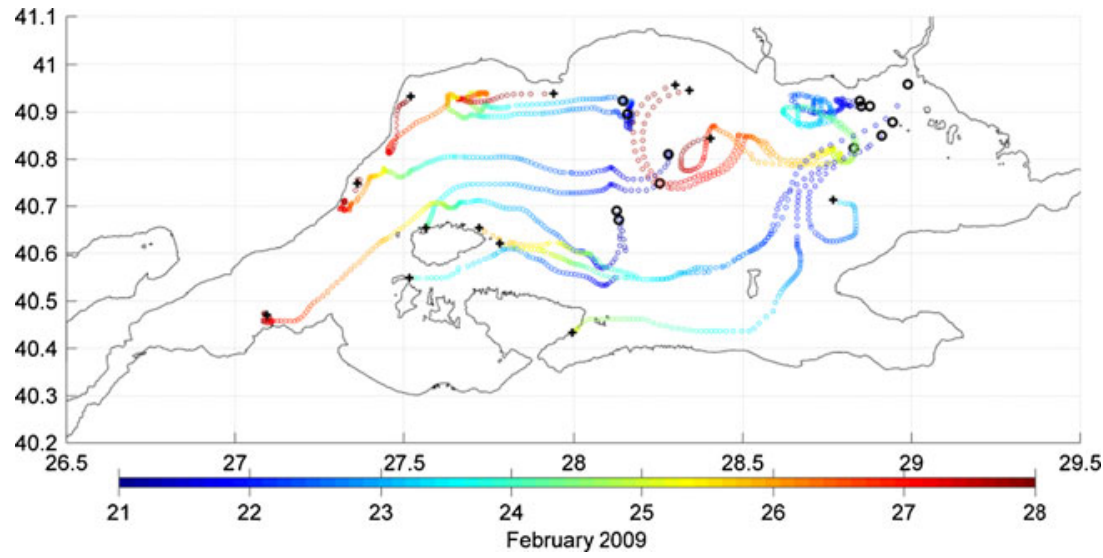


Fig. 15 (a) Daily averaged surface currents $(\mathrm{m} / \mathrm{s})$ and temperature $\left({ }^{\circ} \mathrm{C}\right)$ from 26 February, (b) daily averaged surface currents $(\mathrm{m} / \mathrm{s})$ from 27 to 28 February with superimposed drifter trajectories in magenta (white crosses are location at 27 February 00:00 UTC, black stars are locations at 29 February 00:00 UTC) and model SST $\left({ }^{\circ} \mathrm{C}\right)$ snapshot on 28 February 21:00 UTC in color, (c) Multi-channel SST $\left({ }^{\circ} \mathrm{C}\right)$ map from AVHRR onboard NOAA17 from 28 February 19:17

UTC. Model results are from the TSS09 experiment
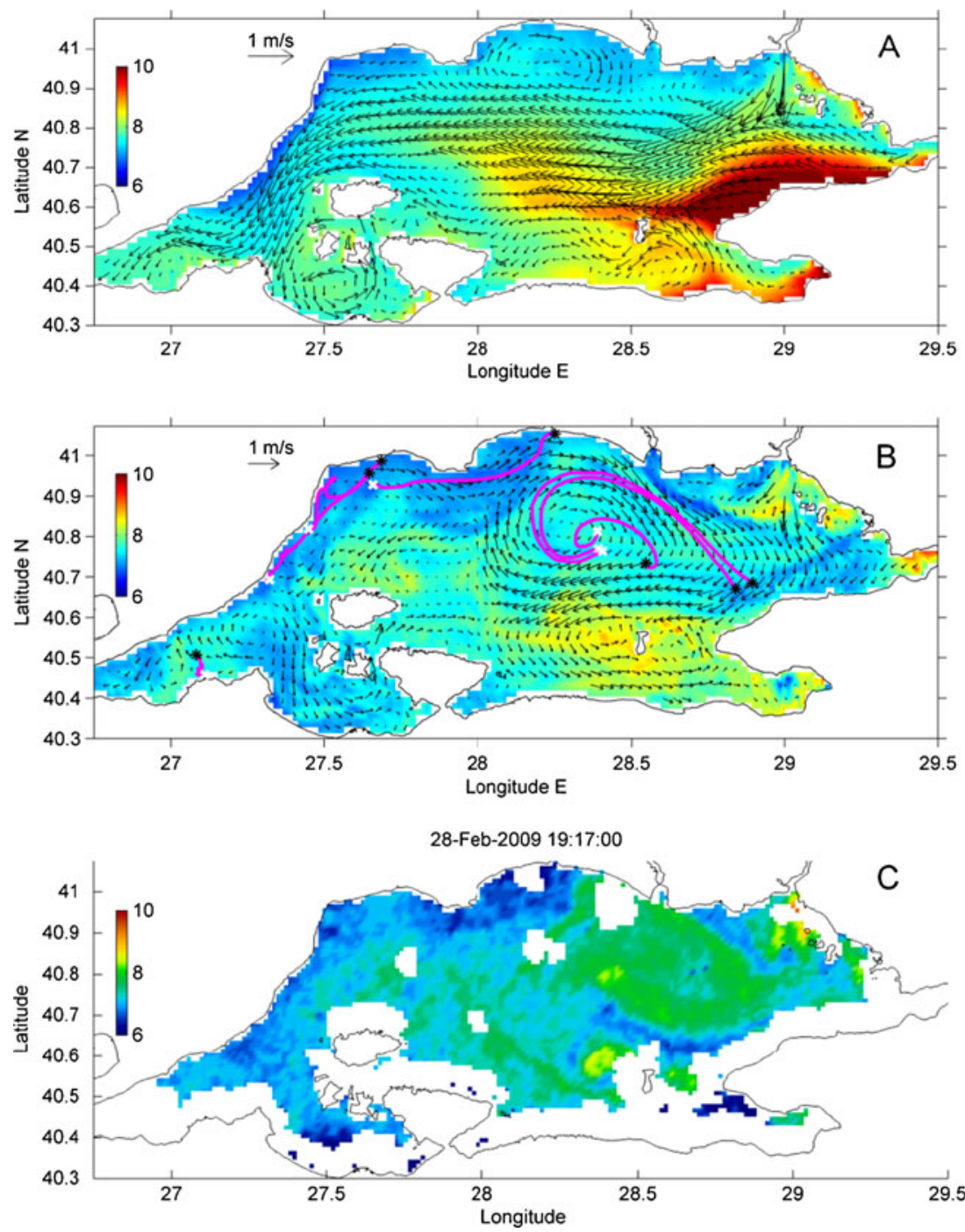

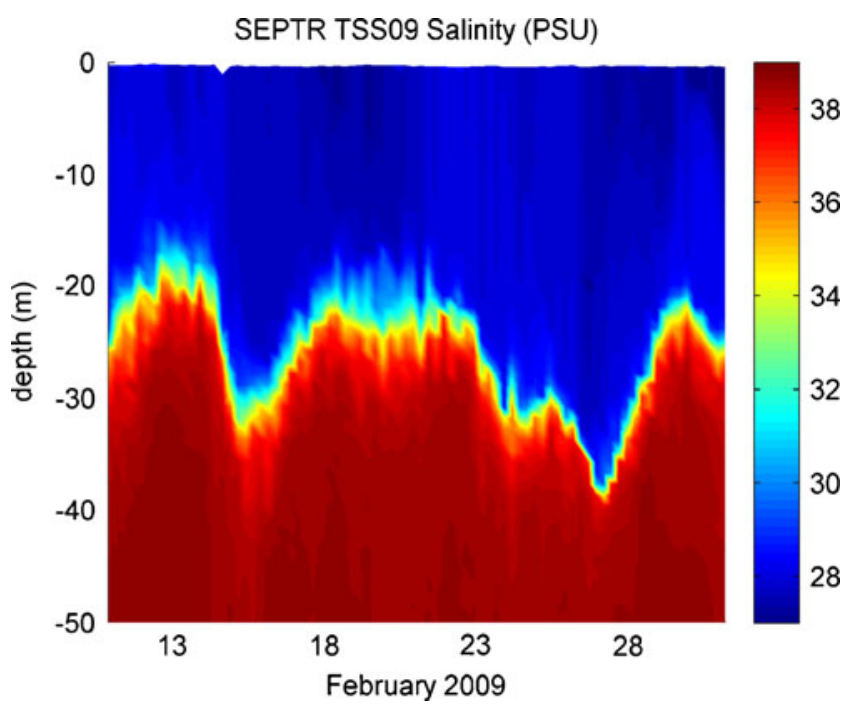

Fig. 16 Time series of salinity profiles from the bottom-mounted profiling SEPTR mooring (see Fig. 1 for location)
$15 \mathrm{~m}$ from the position at rest ( 25 m). The TSS09 model predictions of halocline displacement are well correlated with the observations, but there is an error in the magnitude of the model displacements compared to what was observed (Fig. 17a).

To investigate possible reasons for this error, an alternative idealized experiment was done by closing the boundaries (ST09a, see Fig. 17b), but the results show little difference in the amplitude error from the control run with the open boundaries (TSS09, Fig. 17a). Subsequently, COSMO-ME results were compared to data from the meteorological buoy. This comparison (Fig. 18) suggested that during the strongest impulse of the storm, the meteorological model underestimated the wind magnitude. This error is then squared in the wind impulse, eventually leading to a roughly $30 \%$ underestimation of the impulse during the peak of the event at least at the location of the buoy (Fig. 1). Therefore, the role of wind amplitude was tested in another idealized experiment (ST09b) where the 

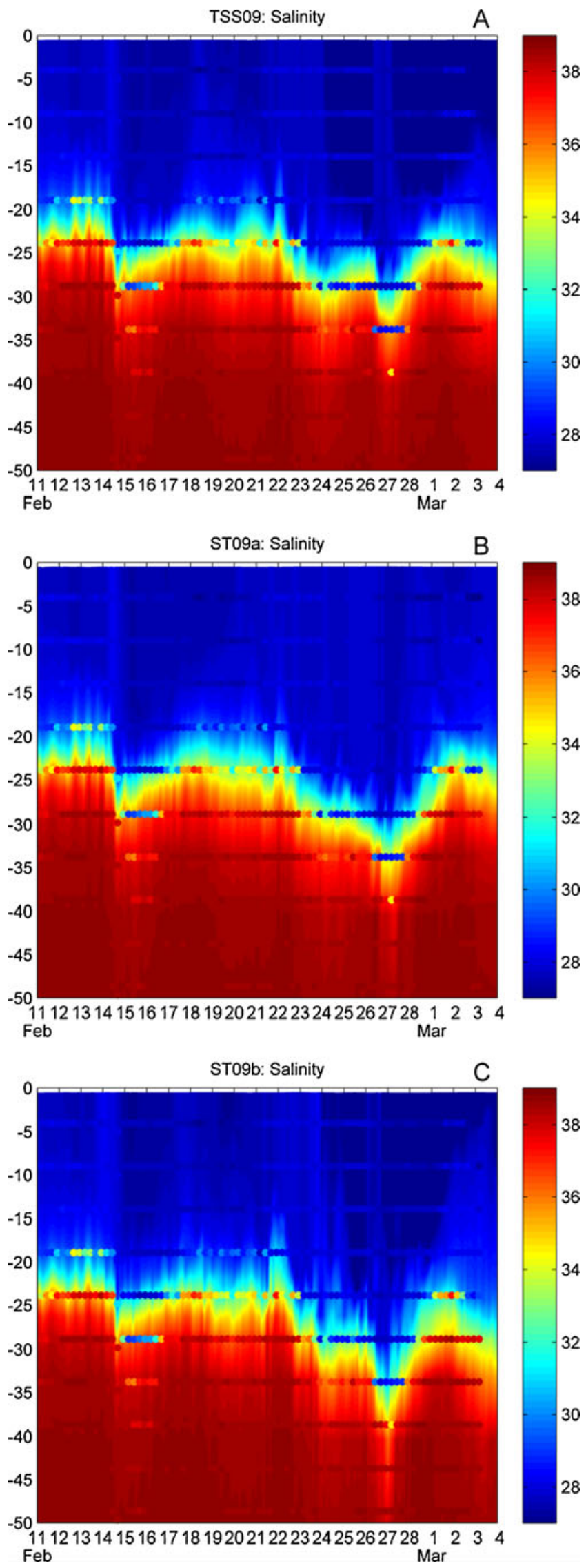

Fig. 17 Model results at the SEPTR location from experiments TSS09 (a), ST09a (b), and ST09b (c). For enhanced readability and direct comparison, SEPTR data are superimposed on model time series every $5 \mathrm{~m}$ depth from $-3 \mathrm{~m}$ down to $-48 \mathrm{~m}$

ocean model was forced with wind fields from the meteorological model scaled to the actual measurements from the buoy. This scaling is not meant to provide an improved "wind product", but was just intended to test to the first-order approximation if the underestimation of the wind magnitude during the peak of the storm may play a role in the underestimated halocline displacement. The scale factor was applied uniformly over all model grid points; it does not include any spatial decorrelation scale or any effect on wind direction. Accounting for such possible factors is likely not critical during the late February storm, when the wind forcing, according to the model, is rather uniform (Fig. 19). The scaling factor is estimated every time step; when the wind from the buoy and from the
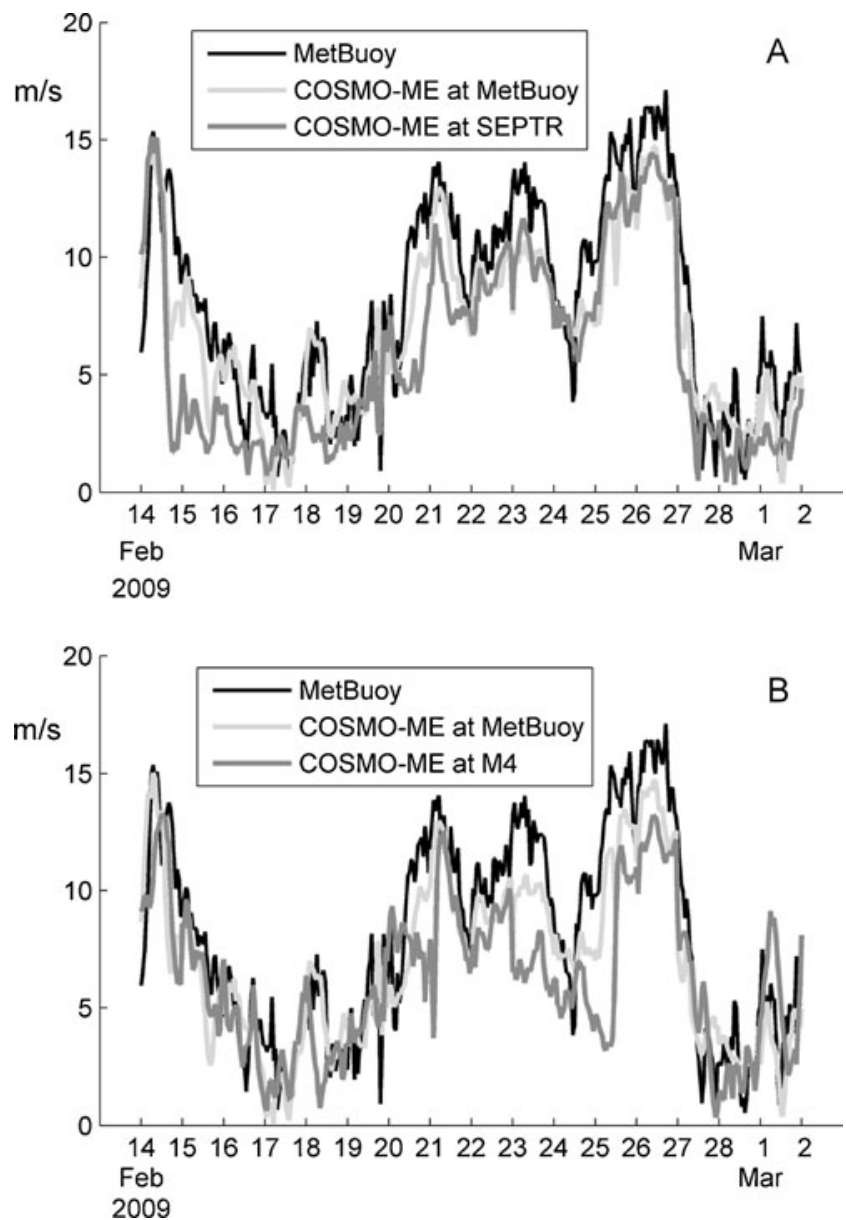

Fig. 18 a Ten-meter wind speed from the meteorological buoy, COSMO-ME model at buoy location, and COSMO-ME model at SEPTR location (upper panel), (b) 10-m wind speed from the meteorological buoy, COSMO-ME model at buoy location, and COSMO-ME model at mooring M4 location (lower panel). Units are meters per second. The locations are given in Fig. 1 
Fig. 19 COSMO-ME $10-\mathrm{m}$ wind field $(\mathrm{m} / \mathrm{s})$ on 26 February 2009, 12:00 UTC

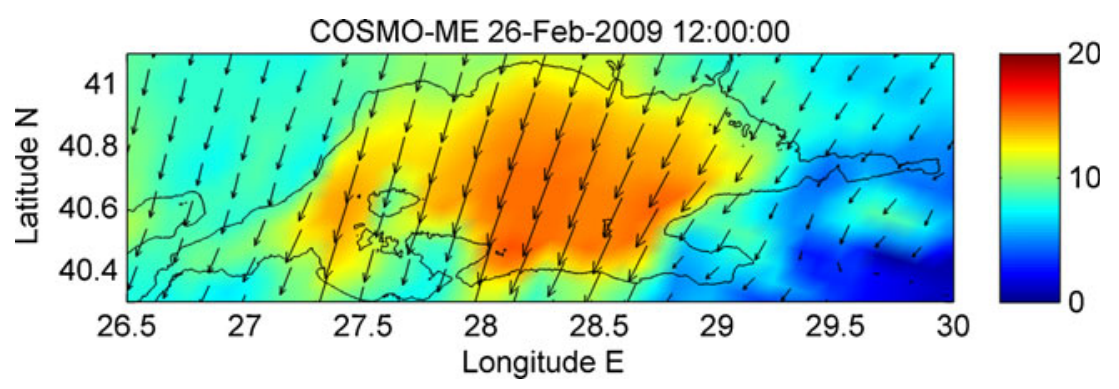

model agree in magnitude, its value is set to one for that time step. Indeed, increasing the model wind speed (and thus the model wind impulse) did lead to a reduction in the model halocline displacement error during the storm in late February. Results are shown in Fig. 17c.

The other pycnocline displacement in Fig. 16 that occurred in mid-February is not correctly simulated in any of the experiments (TSS09, ST09a, ST09b; Fig. 17). The reason for this is likely associated with the wind variability over the basin during that storm. Although the comparison between buoy measurements and model wind at the same location does not suggest major discrepancies, the model wind at the SEPTR location was considerably lower than the model wind in the central part of the basin (Fig. 18a). The lack of wind observations nearby the SEPTR location prevents us from understanding if the underestimated pycnocline displacement in mid-February is due to incorrect dynamics in the model, or to inaccurate meteorological forcing, or to some other factor. In order to shed some light on the spatial variability of the wind forcing during the event, Fig. 20 shows the wind field retrieved from a satellite-borne synthetic aperture radar (SAR) image acquired by the European satellite Envisat on 16 February 2009, 08:13 UTC. The SAR ocean surface winds were retrieved utilizing the wind field retrieval tool, WiSAR, developed at the Helmholz Center Geesthacht, Germany (Horstmann and Koch 2005). Wind directions are extracted from the orientation of the wind-induced streaks visible in the SAR image. The wind speeds are retrieved utilizing the geophysical model function Cmod5 (Hersbach et al. 2007) that relates the SAR retrieved normalized radar cross section, incidence angle and wind direction to the $10 \mathrm{~m}$ neutral wind speed. Although the snapshot was acquired in the spin-down stage of the storm, the wind field derived from the SAR suggests that COSMO-ME was likely underestimating the wind speeds in the western side of the domain. In this situation, the simple scaling used in ST09a could not compensate for such inaccuracies in the wind forcing.

On the eastern side the behavior is generally opposite to that of the western side (Fig. 21). Here, data from mooring NURC-M4 (Fig. 1) were used to obtain time series of temperature (salinity was not available) at a few depth levels. COSMO-ME winds at the location of the mooring M4 (Fig. 18b) are lower than in the western side (i.e., the location of the meteorological buoy) during the late February storm. A sustained peak can be seen in the last 2 days, in accordance with the pycnocline uplift indicated
Fig. 20 Ten-meter wind field retrieved from the advanced SAR aboard the European satellite ENVISAT on 16 February 2009, 08:13 UTC (upper panel) and COSMO-ME $10-\mathrm{m}$ wind field on 16 February 2009, 08:00 UTC (lower panel). Units are meters per second. Wind speeds on the SAR snapshot are provided at $500-\mathrm{m}$ pixel size, while wind directions are at 5-km pixel size
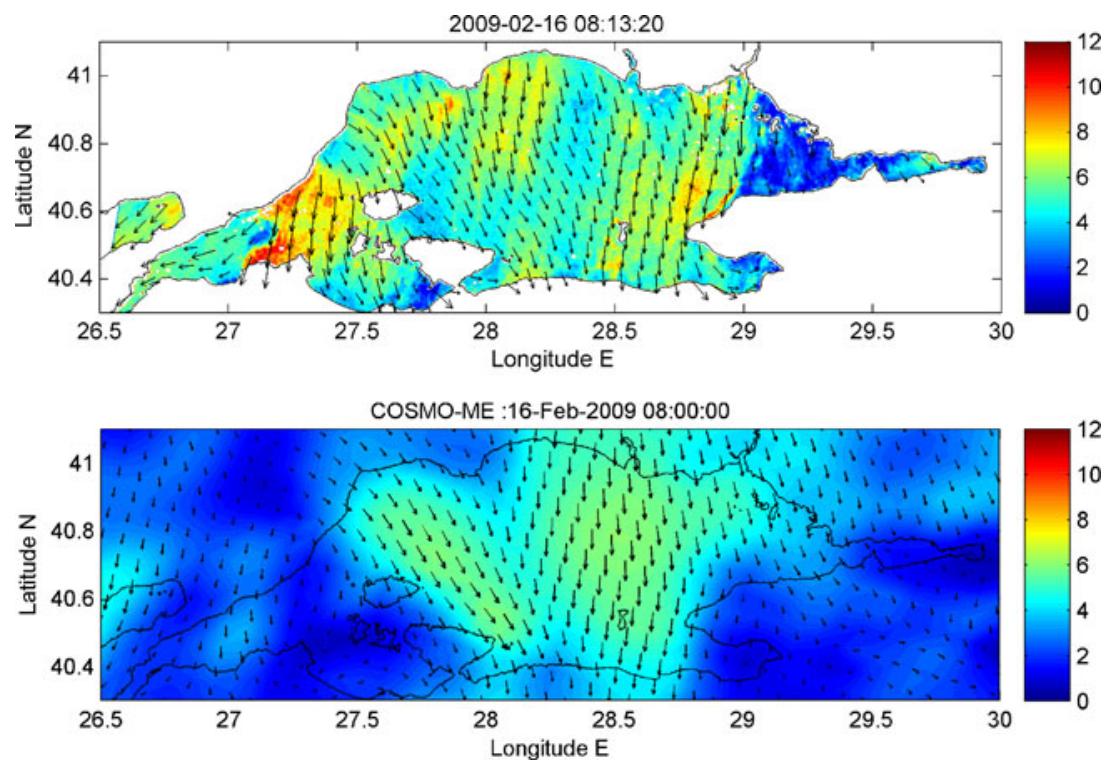

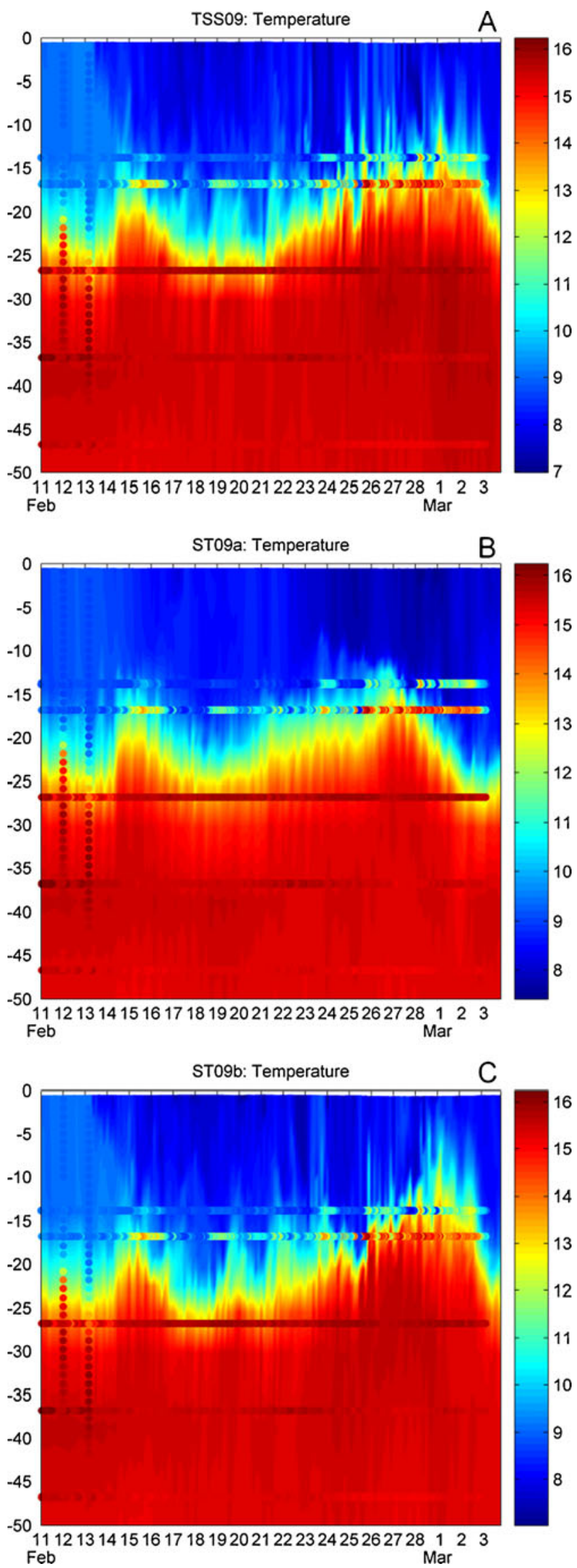

Fig. 21 Model results at the NURC-M4 mooring location from experiments TSS09 (a), ST09a (b), and ST09b (c). NURC-M4 mooring temperature data are superimposed on the model temperature time series at all available depths $(-14,-17,-27,-37,-47 \mathrm{~m})$. Two CTD profiles carried out nearby the mooring on 12 and 13 February are also superimposed

by the mooring sensor at $17 \mathrm{~m}$ (Fig. 21). When the storm spins down on 27 February (Fig. 18b), the thermocline does not relax back to pre-storm conditions $(\sim 25 \mathrm{~m})$ but rather stays at around $15 \mathrm{~m}$ for several more days. The control run (TSS09, Fig. 21a) correctly simulates this behavior. In the ST09a run with closed boundaries (Fig. 21b), the model thermocline relaxes back after the storm, in disagreement with the observations, but in agreement with what could be expected from the significant decrease of the wind forcing (Fig. 18b). Thus, it can be concluded that the SOI flow plays an important role in the thermocline behavior at this location and it can cause significant departures from pure wind-driven theoretical upwelling dynamics near the strait.

\section{Discussion}

The circulation of the Sea of Marmara is composed of semipermanent features, such as a meandering jet and a major anticyclonic eddy. Interplay between the straits inflow/ outflow and the atmospheric forcing control the strength and location of the circulation and these main features. Variability of these two forcing factors can result in strengthening/weakening and relocation of these features. Conversely, from the modeling point of view, uncertainties in the lateral and surface boundary conditions lead to uncertainties in location and strength of the features.

Small-scale cyclonic eddies are found frequently in the southeastern and southern shelf areas. The driving mechanism of these eddies seems to be the local vorticity provided by the orography-induced wind curl of northeasterlies, which are the most frequent winds in the area. However, other mechanisms not discussed here, such as horizontal shear and baroclinic instabilities, could also play a role. Further investigation of these other mechanisms is needed. The cyclonic eddies are usually associated with divergence (i.e., upwelling) that can have a strong impact on the local marine ecosystem, and indeed the southern area is recognized for the highest primary production rates in the Marmara basin (Ergin et al. 1993).

Overall model results are in agreement with the observations collected during the TSS experiments. Some discrepancies arise from the difficulty in simulating the right position in space and time of the active mesoscale features. The correct representation of the sharp pycnocline in the Sea of Marmara is also a challenge for the ocean model, and it may require an inclusion of better vertical 
mixing discretizations. Lastly, skills are limited near the straits, which are certainly partly caused by linearizations and lack of the grid refinement there. In future modeling efforts, some improvements could be made such as, a use of composite grids, an increase of the resolution in the straits, and/or a shifting of the open boundaries into the Black Sea and the Aegean Sea in order to better resolve the non-local forcing. Indirectly, some information on non-local forcing was included in this application through the nudging assimilation of the volume transport observations in the straits, but a sustained observational network there would have to be put in place for the same to be done for future modeling studies.

A remarkable response of the Sea of Marmara to passing disturbances is the large displacement of the pycnocline. Although a dynamical response is expected, this response had not been clearly documented until now. Northeasterlies (such as those that occurred in late February 2009) trigger pycnocline deepening in the western part of the basin, presumably related to wind setup against the western boundary. In the eastern part of the basin, the pycnocline rises, as might be expected, but the response seems to be related to both wind setup and flow from the SOI. Model results did not perfectly match the observed displacement; besides possible internal dynamical errors in the ocean model, the results were found to be sensitive to the correct representation of the wind impulse by the atmospheric model. On the eastern side of the basin, the outflow from the SOI and the surfacing of the pycnocline might increase the mixing/entrainment of waters and nutrients from the lower layer.

\section{Conclusions}

During the framework of the TSS08 and TSS09 experiments carried out in fall 2008 and winter 2009, a set of realistic and idealized numerical ocean modeling simulations were used to study the general circulation of the Sea of Marmara with a particular emphasis on the dynamics of the upper layer. Our numerical model solutions produce a general circulation in the Sea of Marmara that is consistent with previous knowledge of the circulation drawn from past hydrographic measurements. At the same time, comparisons between the realistic experiment results and the idealized experimental results illuminate the role various dynamics play in determining the Sea of Marmara circulation and pycnocline structure. Both the wind curl and the strait flows are found to influence the strength and location of the main semi-permanent features of the circulation as well as to influence the strength and location of the various mesoscale cyclonic and anticyclonic features that can occur throughout the basin. Large displacements of the pycnocline depth were observed during the sea trials. These displacements can be interpreted as storm-driven upwelling/downwelling dynamics, however, with lateral advection from the straits also playing a role. In fact, in the western part of the domain, the wind impulse strength was found to be primarily important in determining the pycnocline response to northeasterly winds, while in the eastern part of the basin, close to the southern SOI, the strait flow was found to interact with the wind-driven response in determining the resulting pycnocline response.

Acknowledgments This work was performed at NURC and funded by the North Atlantic Treaty Organization. All people who contributed to the observational effort during the TSS08 and TSS09 field experiments are deeply acknowledged, as well as the Turkish Navy Office of Navigation, Hydrography and Oceanography and the crew of the NR/V Alliance. The work of E. Jarosz and J.W. Book was supported by the Office of Naval Research under Program Element $0601153 \mathrm{~N}$. The work of J. Dykes was supported by the Office of Naval Research under Program Element 0602435N. P.-M. Poulain and R. Gerin acknowledge the Office of Naval Research grant N000140810943.

Open Access This article is distributed under the terms of the Creative Commons Attribution Noncommercial License which permits any noncommercial use, distribution, and reproduction in any medium, provided the original author(s) and source are credited.

\section{References}

Alpar B, Ünlü S (2007) Petroleum residue following Volgoneft-248 oil spill at the Coasts of the Suburb of Florya, Marmara Sea (Turkey): a critique. J Coastal Res 2007(23):515-520

Alpar B, Ÿuce H (1998) Sea-level variations and their interactions between the Black Sea and the Aegean Sea. Estuar Coast Shelf Sci 46:609-619

Beșiktepe Ş, Özsoy E, Ünlüata Ü (1993) Filling of the Sea of Marmara by the Dardanelles lower layer inflow. Deep-Sea Res 40:1815-1838

Beșiktepe Ș, Sur HI, Özsoy E, Latif MA, Oğuz T, Ünlüata Ü (1994) The circulation and hydrography of the Marmara Sea. Prog Oceanog 34:285-334

Bonavita M, Torrisi L (2005) Impact of a variational objective analysis scheme on a regional area numerical model: the Italian Air Force weather service experience. Meteorol Atmos Phys 88:39-52

Budyko K (1974) Climate and life. Academic, San Diego, 508 pp

Burak S (2008) Evaluation of pollution abatement policies in the Marmara Sea with water quality monitoring. Asian Chem 20:4117-4128

Csanady GT (1977) Intermittent "full" upwelling in Lake Ontario. J Geophys Res 82:397-419

Csanady GT (1982) Circulation in the coastal ocean. Reidel, Dordrecht, $279 \mathrm{pp}$

Cushman-Roisin B, Asplin L, Svendsen H (1994) Upwelling in broad fjords. Cont Shelf Res 14:1701-1721

Demyshev SG, Dovgaya SV (2007) Numerical experiment aimed at modeling the hydrophysical fields in the Sea of Marmara with regard for Bosporus and Dardanelles. Phys Oceanogr $17: 141-153$

Dogan E, Burak S (2007) Ship-originated pollution in the Istanbul Strait (Bosphorus) and Marmara Sea. J Coastal Res 23:388-394 
Ergin M, Bodur MN, Ediger D, Ediger V, Yilmaz A (1993) Organic carbon distribution in surface sediments of the Sea of Marmara and its control by the inflow by adjacent water masses. Mar Chem 41:311-326

Fairall CW, Bradley EF, Hare JE, Grachev AA, Edson JB (2003) Bulk parameterisations of air-sea fluxes: updates and verification for the COARE algorithm. J Clim 16:571-591

Flather RA (1976) A tidal model of the north-west European continental shelf. Mem Soc R Sci Liege 6:141-164

Haidvogel DB, Arango H, Budgell WP, Cornuelle BD, Curchitser E, Di Lorenzo E, Fennel K, Geyer WR, Hermann AJ, Lanerolle L, Levin J, McWilliams JC, Miller AJ, Moore AM, Powell TM, Shchepetkin AF, Sherwood CR, Signell RP, Warner JC, Wilkin J (2008) Ocean forecasting in terrain-following coordinates: formulation and skill assessment of the regional ocean modeling system. J Comput Phys 227:3595-3624

Hersbach H, Stoffelen A, de Haan S (2007) An improved C-band scatterometer ocean geophysical model function: CMOD5. J Geophys Res 112:C03006. doi:10.1029/2006JC003743

Hodur RM (1997) The Naval Research Laboratory's Coupled Ocean/ Atmosphere Mesoscale Prediction System (COAMPS). Mon Wea Rev 125:1414-1430

Horstmann J, Koch W (2005) Measurement of ocean surface winds using synthetic aperture radars. J Oceanic Eng 30 (3):506-515

Jarosz E, Teague WJ, Book JW, Beșiktepe Ș (2011) On flow variability in the Bosphorus Strait. J Geophys Res (in press)
Karaca M, Deniz A, Tayanç M (2000) Cyclone track variability over Turkey in association with regional climate. Int $\mathrm{J}$ Climatol $20: 1225-1236$

Margolin L, Smolarkiewicz PK (1998) Antidiffusive velocities for multipass donor cell advection. SIAM J Sci Comput 90:7-929

Shchepetkin AF, McWilliams JC (1998) Quasi-monotone advection schemes based on explicit locally adaptive dissipation. Mon Wea Rev 126:1541-1580

Shchepetkin AF, McWilliams JC (2003) A method for computing horizontal pressure-gradient force in an oceanic model with a non-aligned vertical coordinate. J Geophys Res 108(C3)):3090. doi:10.1029/2001JC001047

Shchepetkin AF, McWilliams JC (2005) The regional ocean modelling system: a split-explicit, free-surface, topography-followingcoordinates ocean model. Ocean Model 9:347-404

Steppeler J, Doms G, Shatter U, Bitzer HW, Gassmann A, Damrath U, Gregoric G (2003) Meso-gamma scale forecasts using the nonhydrostatic model LM. Meteorol Atmos Phys 82:75-96

Trigo IF, Davies TD, Bigg GR (1999) Objective climatology of cyclones in the Mediterranean region. J Clim 12:1685-1696

Trigo IF, Bigg GR, Davies TD (2002) Climatology of cyclogenesis mechanism in the Mediterranean. Mon Wea Rev 130:549-569

Umlauf L, Burchard H (2003) A generic length-scale equation for geophysical turbulence. J Mar Res 61:235-265

Warner JC, Sherwood CR, Arango HG, Signell RP (2005) Performance of four turbulence closure models implemented using a generic length scale method. Ocean Model 8:81-113 